\title{
Poly(lactic acid)-silkworm silk fibre/fibroin bio-composites: A review of their processing, properties, and nascent applications
}

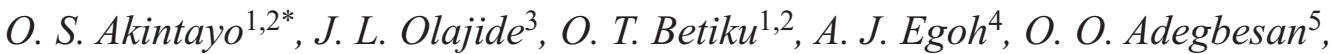 \\ O. O. Daramola ${ }^{6,7}$, E. R. Sadiku, D. A. Desai ${ }^{3}$
}

${ }^{1}$ Université Grenoble Alpes, Grenoble INP-PHELMA, 38000 Grenoble, France

${ }^{2}$ University of Augsburg, 86159 Augsburg, Germany

${ }^{3}$ Department of Mechanical and Automation Engineering, Tshwane University of Technology, Pretoria, South Africa

${ }^{4}$ Department of Mechanical Engineering, Florida Agricultural and Mechanical University - Florida State University College of Engineering, Tallahassee, Florida, United States of America.

${ }^{5}$ Project Development and Design Department, Federal Institute of Industrial Research, Oshodi, (FIIRO) Nigeria

${ }^{6}$ Institute of NanoEngineering Research (INER) \& Department of Chemical, Metallurgical and Materials Engineering (Polymer Technology Division), Tshwane University of Technology, Pretoria, South Africa

${ }^{7}$ Department of Metallurgical and Materials Engineering, Federal University of Technology Akure, Nigeria

Received 31 December 2019; accepted in revised form 22 March 2020

\begin{abstract}
The past few decades have witnessed an upsurge in the utilization of natural fibres in green materials advancement. This rise can be linked to calls from stakeholders, around the world, on the issue of sustainability and eco-friendliness. A shift from the utilization of non-biodegradable sources to renewable sources is a current area of intense research, which also stimulates industrial attention. Amongst the creations of nature, silkworm silk fibres have attracted considerable interest from materials science researchers. Inferable from its amazing biocompatibility, bioresorbability, and biodegradability, silkworm silk strands have been used in the improvement of polylactic acid/silk fibre biocomposites. Hence, with the continued use of these biocomposites in industrial and biomedical applications, it has become necessary to look at the systematic progress made in its processing, overall property improvements, and various applications. This review article also presents the challenges facing the advancement of this biocomposite, the suggested solutions and concludes with anticipated future trends.
\end{abstract}

Keywords: biocomposites, poly-lactic acid, silkworm/silk fibres, biomedical applications, industrial applications

\section{Introduction}

The growing environmental and sustainability concerns connected with the utilization of composites reinforced with artificial fibres have prompted a significant spotlight on green materials innovation. Materials researchers have done substantial investigations in the use of natural materials for the development of high-performance materials because of their points of interest, such as easy processability, lightweight, biodegradability and low-cost amongst others
[1]. Some high-quality animal-based fibres, such as silk, wool, and chicken feathers, have been utilized as fibre reinforcements [2-4]. The concern is not only limited to the environment but also bio-engineered materials. The need to develop biocompatible, biodegradable, light-weight and less stiff medical implants, has led to the concept of biomaterials. For example, in bone replacement or fixes, stainless steel and titanium have been used as bone plates for many years because of their exceptional biocompatible 
properties. Be that as it may, the utilization of these materials for a long-term bone repair frequently requires multiple surgical operations to remove the plates and other fasteners, and this often causes pain or inconvenience to the concerned patient. Therefore, it is imperative that stiff materials are utilized for making plates for bone repairs [5]. Composites used in this sense can be based on synthetic and natural materials. Typically, for such biocomposites, a biodegradable polymer (natural or synthetic) and a natural fibre/filler are combined [6].

The silkworm silk fibre (also called silk fibre), which is a reinforcing phase of the bio-composite in the current review, has been traditionally used for decades, as biomedical sutures, tissue scaffolds and in textile production [6-9]. Silk is commonly characterized as protein-based material that is spun into fibres by some lepidoptera larvae, for example silkworms, arachnids, scorpions, bugs, caterpillars, and flies [10]. Silk proteins are usually produced inside specialized glands after biosynthesis in the epithelial cells, trailed by secretion into the lumen of these glands, where the proteins vary broadly in composition, structure, and properties, contingent upon the particular source and where it is cultivated [10]. The silk fibres considered in this review are the Tussah silk, originating from the species of wild silkworm called Antheraea pernyi (A. pernyi) and the Bombyx mori silk fibres, artificially cultivated from domesticated mulberry silkworm, which are usually whitetoned. The latter is the most broadly characterized silk fibre, and it is obtained from a cocoon, delivered by the domesticated mulberry silkworm, Bombyx mori and from spiders (Nephila clavipes and Araneus diadematus) $[10,11]$. The production of silk

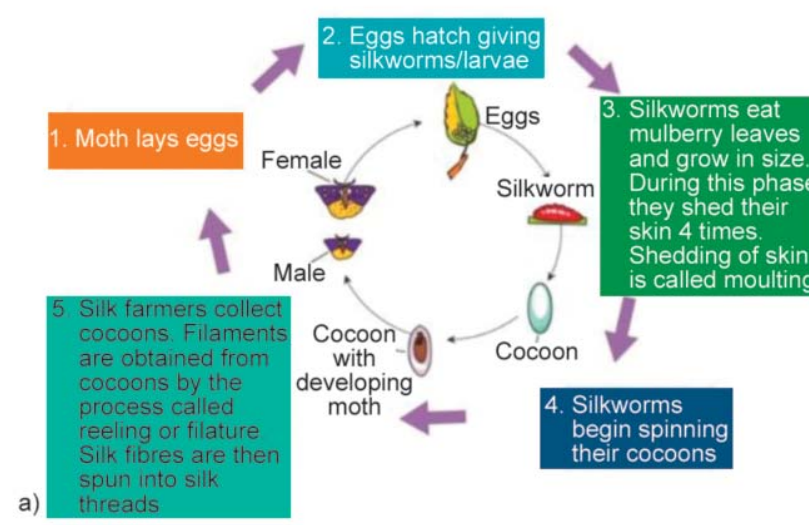

fibres from the domesticated mulberry silkworm is called sericulture.

In sericulture, the silkworms lay hundreds of eggs (between 300-400) at a time, which are carefully stored in hygienic and warm conditions for hatching. A hatched larva is between $60-70 \mathrm{~mm}$ long [12]. The subsequent stage is the feeding period, where the larvae become 10000 times heavier than the weight during the hatching period [13]. In the third step, the silkworm stops eating, and they get ready to spin the cocoons of silk fibres [14]. This is followed closely by a reeling process, where all the cocoons are separated by placing them in hot water, and the silk fibres are obtained by simply unwinding them in the form of threads. $[12,14]$. The sericulture process is presented in Figure 1a.

The acquired silk fibre is a natural protein fibre (also called silk fibroin), which is biodegradable and can be either semi or highly crystalline with a well-aligned structure $[2,15]$. Average crude silk is composed of $22-25 \%$ sericin, $62.5-67 \%$ fibroin, water and mineral salts [16]. The silk fibre has a gland with two cores of fibroin appearing as a paired organ and encompassed by a cementing sericin layer in a structure known as 'bave' $[16,17]$. A SEM micrograph of the cross-section of a silk filament can be seen in Figure $1 b$. On the one hand, fibroin is a single protein that does not dissolve in water, and it has a fibrillary structure. On the other hand the sericin on the fibre has an amorphous structure, and this gummy protein dissolves in the water more than the fibroin [17]. Its crystallinity, crystalline, and amorphous orientations can be characterized by X-ray and electron scattering techniques. Silk fibre possesses higher tensile strength than some synthetic fibres e.g. Kevlar, good ductility

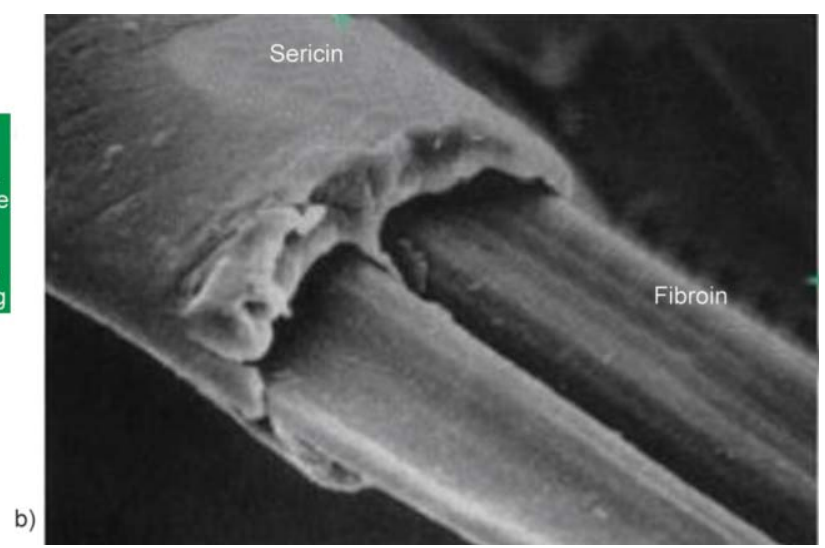

Figure 1. (a) Production of silk fibre from rearing of domesticated silkworm cocoon [14]. (b) A cross-section of a silk fibre filament showing the two fibroin cores surrounded by a sericin layer. Reprinted from [41], with permission from Elsevier. 
and excellent fracture toughness [18-20]. Many of its crystalline phase-related parameters correlate with the tensile mechanical characteristics of silkworm silk fibre [15].

The environmental challenges related to the disposal of conventional plastics have prompted the introduction of biodegradable polymers during the 1980 s, and it was designed to degrade upon disposal, by the organic activity of microorganisms [21]. Biodegradable polymers offer greater advantages and possibilities due to their good biocompatibility, biodegradability, tailorability, bioresorbability, good mechanical properties, high purity level and easy moldability [22]. Their degradation products have low or negligible toxicity; they are metabolized, and eliminated easily when used in-vivo [22]. A commonly used biodegradable polymer is poly (lactic acid) (PLA). Poly (lactic acid) (PLA), also called polylactide are synonymous with the group of aliphatic polyesters, derived from $\alpha$-hydroxy acids, which is chiefly acquired from starch and sugar. PLA is produced either by microbial means [23] or chemical synthesis [24, 25]. A typical illustration of PLA production by microbial route, utilizing starch obtained from feed-stocks, such as; beet sugar, molasses, and barley as potential starting substrates is presented in Figure 2a [23, 26]. Likewise, chemical synthesis is employed to obtain PLA from lactic acid through polymerization processes such as; polycondensation, ring-opening polymerization, and direct methods (e,g azeotropic dehydration). The direct method and ring-opening polymerization are the most generally used methods [24, 25, 27]. A typical chemical synthesis route is presented in Figure $2 b$. Since PLA is compostable and derived from sustainable sources, it is viewed as a promising material to decrease environmental and ecological issues [28]. Poly(lactic acid) (PLA) and its copolymers are the most broadly used engineered biodegradable polymers in medicine $[6,21,29]$. It takes months to years for PLA scaffolds to lose their mechanical integrity, either in-vitro or in-vivo [30]. During biodegradation, PLA degrades into lactic acid, which is finally metabolized and excreted from the host as carbon dioxide and water. It offers, particularly, expanding commercial interest since it is currently conceivable to attain high molecular weight PLA production [5]. Furthermore, PLA can maintain its mechanical properties, even under a humid environment without suffering rapid hydrolysis and thus, PLA can find use in structural applications $[5,30]$. Hence, its wide usage as matrices in the development of PLA/silk fibre biocomposites.

A handful of research works has been conducted in the area of silk fibre-based biocomposites and PLAbased biocomposites. For the former, some works include; silk/chitosan blend [31, 32], silk/poly(butylene succinates) PBS biocomposites [33], and silk fibroin/polysaccharide-sodium alginate blend sponges [34]. In the case of the PLA-based biocomposites, some works include abaca fibre/PLA [35], bamboo fibre/PLA [36], microcrystalline cellulose/PLA [37] and kenaf fibre/PLA [38], composites amongst many others. Several research accomplishments in the development of the two aforementioned composites have provided a conceptual framework for silkbased polymeric composites to be a promising candidate for a wide variety of applications. Past investigations on the effect of silk fibres on polymeric materials, drew the attention of researchers, such as Cheung and coworkers [5, 6, 39], Ho et al. [2], Mei et al. [40], to the potentials of silk fibres, thereby giving these researchers, the motivation to develop fully, biodegradable PLA/silkworm silk fibre biocomposites. In addition, various studies on their structural, thermal, microstructural, and biodegradation properties have been conducted $[2-6,10,21$, 39]. It is the aim of the present article to present a review of their processing routes, the properties highlighted above, and the nascent areas of applications of PLA/silkworm silk fibre biocomposites. As an addendum, limitations, hindering the large scale development of these biocomposites and proposed solutions, are also discussed.

\section{Processing/fabrication techniques \\ 2.1. Criteria for selection of processing techniques}

In order to acquire a defect-free product, it is important to choose the most suitable preparation strategies. Factors taken into consideration by product designers include; the area of the intended application, the desired mechanical and thermal properties, the nature of raw materials to be used, the size and shape complexity of the final product (i.e. part design), and the manufacturing parameters (including production rate and cost) [41]. The composite size and shape complexity are important factors in selecting the processing techniques. For smallsized materials, injection, compression and melt compounding techniques, can be employed since 

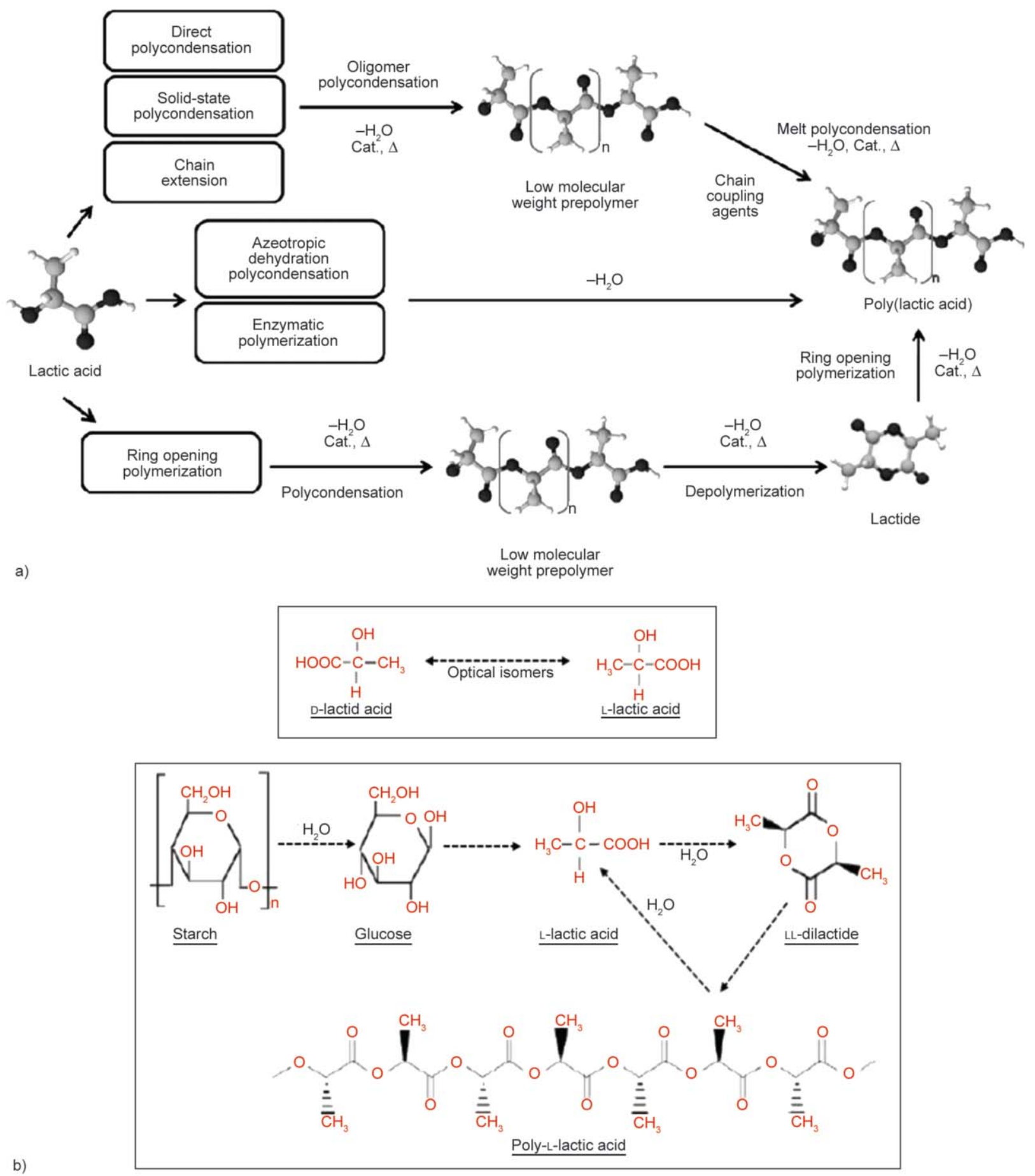

b)

Figure 2. (a) Synthetic routes for PLA production [25] and (b) natural routes for PLA synthesis [26]. Reprinted with permission from Elsevier.

they are high-volume moulding methods and can provide high throughput [42-45]. For large noncomplex products, open moulding processes (e.g. resin transfer moulding) are usually employed. It is employed for products such as; truck bumpers and fenders, spas, sandwich structures found in boats and modern aircraft $[43,45]$. It also includes a vacuum-assisted version, and both processes can combine either hand lay-up or spray-up. Hand lay-up or spray-up can also be used in isolation for composite fabrication [46-48]. Matrix type, the viscosity of the polymer and processing temperature should be considered when choosing an appropriate composite fabrication technology. Additional processing considerations for enhanced performance of fibre-reinforced composites include; fibre-matrix interaction, fibre-to-resin ratio, fibre form, orientation and architecture [49]. 


\subsection{Silkworm silk fibre preparation}

A foremost disadvantage of natural fibre-reinforced polymer composites is the inherent incompatibility between the hydrophilic natural fibres and the hydrophobic polymer matrices. This results in the undesirable properties and performance of the composites. The polymer viscosity is sometimes very high, thereby making it incapable to wet the fibres completely. Consequently, it is important to alter the fibre surface by employing chemical modifications in order to improve the interfacial adhesion between fibre and matrix [37]. In silk fibre composites, the difference in surface characteristics was observed to be the significant reason for poor adhesion between the fibres and matrix. This incompatibility originated from the hydrophilic nature of the silk fibre surface, whereas the polymer surface is often, hydrophobic. On that note, fibres debond and the mechanical strength of the composite decreases. Silk fibres used in this manner could not improve the composite property [50]. Consequently, various interfacial upgrades such as; chemical alkali treatments e.g. mercerization [46,51], physical methods (corona discharge) [52] and silane coupling agents [53], amongst others, have been employed to overcome this difficulty. Also applied, is the environmentally-friendly plasma treatment by Chaivan et al. [54] for the improvement of surface of silk fibre and its hydrophobicity without altering its bulk properties. However, the high cost of plasma treatment has so far restricted its wide usage in the industry. Amongst them all, chemical treatment and in particular, degumming is one of the regularly utilized chemical treatments in fibre-reinforced plastics industry. Degumming involves sericin hydrolysis, breaking amino acid groups into small molecules, and final dissolution of the sericin in water [55]. It increases the number of possible adhesion sites since the surface of the fibre is better exposed upon treatment. Following such treatment, the fibre becomes soft and glossy [56].

As mentioned in the introduction, the upper layer of the silk fibres consists of sericin, and this can be removed by degumming without causing any harm to the fibre itself. Sericin removal is done by placing the fibres in a liquid media. It is discovered that the tensile properties of the fibre increase on the removal of the sericin from the fibre. Some degumming processes, such as: water degumming, soap, degumming by soap-alkali boiling, enzymatic processes, boiling in the acidic solutions, and even genetic modifications have been developed. By using boiling

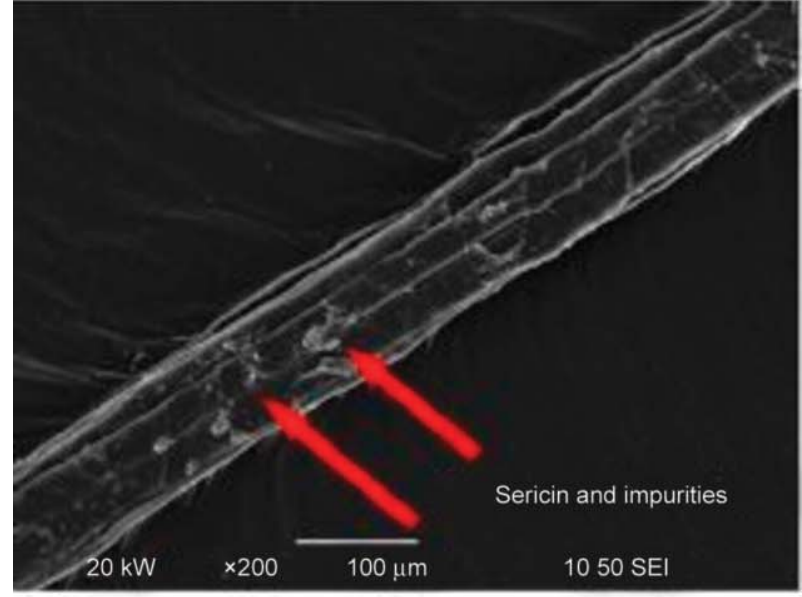

a)

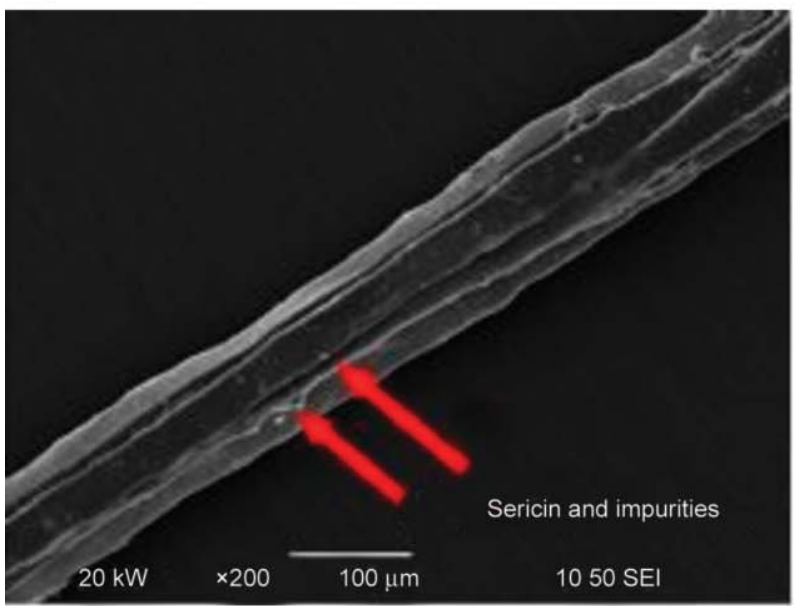

b)

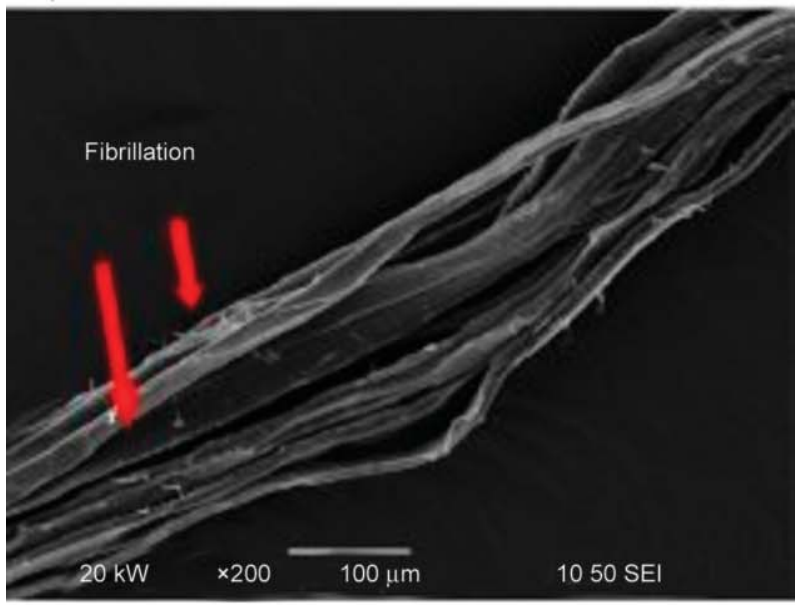

c)

Figure 3. Surface of silk fibres degummed for (a) $0 \mathrm{~min}$ (neat sample) (b) 15 minutes, and (c) 60 minutes. Reprinted from [11], with permission from Elsevier.

water, Ho et al. [11] studied the effect of degumming time on the tensile properties of silk fibres at different times ranging from 15 to 60 minutes. They discovered that increasing degumming time leads to further fibre damage as the hot distilled water causes the removal of sericin coatings and fibroin loss. For the neat fibre 
samples which were not treated with hot distilled water, their surfaces appeared fairly rough due to the presence of sericin coating, as seen in Figure 3a. On the other hand, the fibre sample degummed for 15 minutes exhibited the best tensile property improvements. Its surfaces appeared smooth, and no fibroin damage was found, as observed in Figure 3b. For fibre samples treated after 30, sometimes up to 60 minutes (Figure 3c), though the sericin was removed completely, fibrillation occurred due to longer treatment time.

Strong alkali solutions such as sodium hydroxide $(\mathrm{NaOH})$ and sodium carbonate $\left(\mathrm{Na}_{2} \mathrm{CO}_{3}\right)$ confers relatively harsh irritation to the surfaces of silk fibres $[55,57]$. Based on that, Ho [51] utilized a weaker $\mathrm{NaHCO}_{3}$ alkaline solution to treat silk fibres chemically. When compared with the tensile properties of silk fibres degummed by hot water and strong alkaline solution $[19,55]$, the $\mathrm{NaHCO}_{3}$ showed no severe reduction to the tensile properties of the silk fibre. In order to prove the effectiveness of the surface treatment methods on bonding improvement between the fibre and PLA matrix, Ho [51] performed a micro-bond test to measure the interfacial shear strength (ILSS) of the composites. The composite with degummed silk fibres exhibited better ILSS when compared to the composites with raw fibres, since the treatment led to increased friction and enhanced mechanical interlocking between the fibres and the PLA matrix. Although the fibre treated with hot water exhibited higher ILSS (37.8 MPa) when compared to the $\mathrm{NaHCO}_{3}$ treated fibre (30.1 MPa), the latter still exhibited better tensile strength when compared to the former. In this situation, a conflict arises between higher ILSS or tensile strength and the final selection of the best chemical treatment would require a compromise. Describing another degumming process, but using soap-alkali as one of the constituents of the 'de-gummer', silk fibre is immersed in a container consisting of a fibre-to-liquor ratio of 1:40. Also, $7 \mathrm{~g}$ soap and $1 \mathrm{~g}$ soda per liter were added to the solution, which was then boiled for one hour. The fibre was then thoroughly dried in order to remove the residual moisture.

Yuksek et al. [56] carried out degumming processes through both the conventional (soap-alkali boiling) and ultrasonic energy methods with three different natural soaps (laurel, olive, and turpentine). With credit to the ultra-sonication process, the authors discovered that the degumming process performed with turpentine soap, yielded positive outcomes in terms of weight loss, whiteness degree, and mechanical properties. The sericin layer available on the exterior surface was expelled totally in the ultrasonic energy method, where turpentine soap was used as compared to the conventional method. In addition, the fibrillar structure of the silk fibre turned out to be progressively obvious. Overall, they found the ultrasonic energy method to be energy-saving and economical. In present times, when efforts are to diminish the dangers of environmental pollution from such chemical wastes, the ultrasonic method holds promise for the treatment of silk fibres, thus guaranteeing environmental sustainability. Generally, soap-alkali boiling and chemical treatment, previously described, is recommended; however, it is not environmentallyfriendly considering the necessary chemical waste disposal. Hence, the enzymatic process and even the ultrasonic method are preferred [56, 58]. The selection of the right silk fibre treatment boils down to a trade-off between the intended properties desired, the fibre source, the availability of the treatment method, costs and environmental considerations.

\subsection{Processing/fabrication of PLA/silkworm silk fibre composites}

The majority of the PLA/silk fibre composites developed are fabricated by using a process similar to those used for traditional fibre-reinforced polymer matrix composites (FRPMCs). In this regard, there are broad classes, known as the open mould and closed mould processes. The processing of PLA/silk fibre composites, as reported in the literature, is also classified broadly into the open mould process-hand layup, hand spray-up, autoclave, and the closed mould process-the melt compounding-injection moulding combination. The unconventional additive manufacturing route is also discussed to shed light on how it has been implemented in the development of PLA/silk fibre composites

\subsubsection{Two-step melt compounding-injection moulding process}

The melt compounding-injection moulding process is a combination of two fabrication steps. The initial step is the compounding of the raw material, which is followed by the injection-moulding step in an injection moulding machine. The compounding of a polymer is a common process in which a pre-defined measure of the blend, which contains polymer melt 
and fibre is constrained into mould cavities. This system is, likewise, suitable for polymer composites that can not be handled by solution blending, owing to their insolubility in regularly utilized solvents. It, is likewise, a technique free from the use of solvents, and by virtue of that, fibres can be added to polymer matrices in the molten state [59]. Moreover, the operation is environmentally-friendly, direct, industrially and commercially suitable. The equipment which is used in this technique consists of an extruder, two roll mill, and an internal mixer. The polymer matrices used in this process are mostly in the form of pellets, such that with the chopped fibres, they feed individually through a funnel-shaped feed hopper into a heated compression barrel, consisting of rotating single or twin screw. The purpose of the heating the barrel is to transform the pristine polymer pellets into a viscous melt, which can be plunged through a sprue nozzle and forced into closed metal-mould cavities of desired shapes and dimensions. The mould is tightly clamped against the injection pressure, where the polymer solidifies, holding in place, the orientation and initial distribution of fibres. The composite is then removed from the closed mould of the desired shape after it has sufficiently cooled [41].

This technique can be done either on an industrial scale or a laboratory scale by using a Rapra SingleScrew Extruder as demonstrated by Daramola et al. [60]. Similarly, Zhao et al. [2] fabricated PLA/silk biocomposites by melt compounding with a Thermo Haake MiniLab twin-screw micro extruder at $180^{\circ} \mathrm{C}$. For them to produce dumb-bell specimens, they transferred the mixture to a Thermo Haake, a small scale injection-moulding machine in which the barrel and the mould temperature parameters were pre-selected. A major advantage of this technique is that it is rapid and inexpensive. Silkworm fibres, which are used in this technique, are cut gently into short fibres of a critical length. An example is the work of Zhao et al. [2] in which they chose $5 \mathrm{~mm}$ as the optimum length for the short silk fibres to be incorporated in the PLA matrix. This critical fibre length criterion is very important since it ensures that stress is fully transferred from the matrix to the silk fibre and that the silk fibre can operate to its full loading capacity, assuming good interfacial bonding is satisfied. Therefore, it is necessary to determine the critical length of the fibre before compounding carefully and injection moulding processes are performed in a 2-step operation. It is entirely expected that loading-up a polymer matrix with high fibre content would increase the stiffness and strength of the composites developed. However, in practice, the injection moulding process would constrain the amount of fibres that can be injected because of fibre cluttering/attrition, limited gate and sprue of the extruder and increased viscosity of the fibre/polymer mixture [41]. In general, in order to guarantee a seamless injection moulding process, obtain optimal properties of the resulting natural fibre composites and avoid the development of residual stress, which causes warpage, stress cracking and long-term distortion, the process, and geometrical/ material parameters should be optimized. Process parameters, such as; the melt temperature, injection and screw speeds, injection pressure, and the mould temperature should be predetermined in order to obtain the best optimum condition for the injection moulding process of PLA/silk fibre composites [51]. A possibility of using a single step injection moulding process has also been explored for PLA/raw continuous long silkworm silk fibre composites [61].

\subsubsection{Compression moulding}

Compression moulding is a large-scale fabrication method, in which heated hydraulic presses, with precisely matching metal moulds, are used. The matrix and reinforcing materials are at first mixed, and the blending and feeding steps can be automated. Parts with short cycle times in long series are the typical compression moulded products. Examples of products from this manufacturing technique are automotive parts, covers, and insulating parts [45]. Compression moulding offers several advantages, e.g. minimal degradation of the resulting composites due to lower shear rate, and a low amount of material waste [62]. Silk fibre composite moulded products with large surface area, good mechanical properties, and performance can be produced by this technique. Unidirectional silk fibre-reinforced PLA composite was prepared by Memon and Nakai [63]. The parallel yarns of the PLA and silk fibres were wound and consolidated. Elastic modulus improvement was achieved, and their study can serve as a recommended manufacturing guide, with respect to the material selection and process optimization for compression moulding of unidirectional bio-composites.

\subsubsection{Manual lay-up}

Manual or hand-lay up in a suitable metal mould can also be used to prepare these materials, in which the 
polymer melt is poured onto the silk fabric inside the mould and a metallic roller is used to aid impregnation, expel trapped air and excess resin. This method can also be combined with a vacuum bagging system, which aids in the removal of air from the polymer melt by using suitable vacuum pressure, thus avoiding subsequent voids that may form in the finished part. Mangat et al. [64] utilized the hand-lay manual approach, and they were able to achieve considerable distribution and thickness of the inserts in PLA/silk fibre hybrid composites. However, they recommended the use of an automatic fibre placement system in order to achieve better uniformity and thickness. Casting has also been used for the preparation of silk fibre composites [62].

\subsubsection{Additive manufacturing of PLA/silkworm silk fibre composites}

The interest in additive manufacturing abilities has risen due to its ability to produce functional finished parts with near-net shape and low material waste. Polymers and metals are considered as the mainstream materials for additive manufacturing (also referred to as 3D printing), with composites as the emerging areas of interest [65]. In spite of the fact that $3 \mathrm{D}$ printed parts have so many advantages over the conventional methods, some printed polymeric parts often suffer from poor mechanical characteristics, e.g. low strength, which in turn, limits their applications in fully functional and load-bearing components [66]. Be that as it may, the optimization of the operation parameters, such as build orientation and feed rate, has been explored for improving the mechanical properties of thermoplastic parts in a couple of studies [67]. Notwithstanding the parameter optimization, 3D printed thermoplastic parts still exhibit lower properties, when compared to those obtained by conventional polymer processing methods, e.g. compression or injection moulding [68]. In addition, the quality of fully printed parts regarding dimensional accuracy and surface finishing is affected by part multi-faceted design, the corresponding print path and the differential cool-down, and solidification of the individual raster, among other variables. These downsides have restricted the wide industrial utilization of 3D printed thermoplastic parts [66]. On that note, improving the mechanical properties of plastic materials would require reinforcement with fibres in order to produce functional and structural properties that are non-attainable in the matrix alone.
For polymer and polymer reinforced components, various techniques, such as; Stereo-lithography (SLA) or Laminated Object Manufacturing (LOM) with photopolymer liquids as feedstock [69], Selective Laser Sintering (SLS) in which polymer powders are used as feed materials [70], and Fused Deposition Modelling (FDM) [71], have been developed.

Fused Deposition Modelling (FDM) is one of the 3D printing innovations that is broadly used for polymer composites [66, 72-75]. It is suitable for producing polymer matrix composites because of the possibility to use multiple nozzles with the loading of different materials, thus leading to short manufacturing times. A criterion for its use requires the feed material to be in filament form. At times, a homogenous dispersion and the removal of formed voids during manufacturing can be a bottleneck. In addition, a compromise in the melt viscosity of the polymer is required, such that it is low enough for extrusion and high enough for structural rigidity [72]. Despite these criteria and constraints, FDM offers the advantages of low cost, high speed, simplicity, and simultaneous deposition of diverse materials $[75,76]$. FDM printers operate by controlled extrusion of filaments, as shown in Figure $4 \mathrm{a}$. In this technique, the filaments feed into an extruder and melt into a quasi-liquid state at the nozzle, enabling it to be extruded layerby-layer onto the build platform, where layers are fused to solidify into final parts. This extruder is normally mounted onto a CNC (Computer Numerical Control) gantry, enabling complex geometrical patterns to be printed. Once a layered pattern is complete, either the printing platform drops down, or the extruding orifice rises by the layer thickness to deposit a subsequent layer. This way, 3D objects can be fabricated through the progressive deposition of layers $[72,77]$. A typical example of a 3D printer and the PLA filament formed is shown in Figure $4 \mathrm{~b}$.

The introduction of silk fibre/filament into this innovative field is due to the remarkable enhancements and expansion in properties of the subsequent 3D printed materials that exhibit excellent properties with multipurpose applications. Specifically, there is increasing enthusiasm in the development of high-performance composites, suitable for 3D printing that can be achieved via the introduction of fibres with unique properties, e.g. silk. Silk fibre possesses excellent mechanical properties, which make it a great candidate for the reinforcement of several polymers [78]. Shubra et al. [79] in their study, reported that 


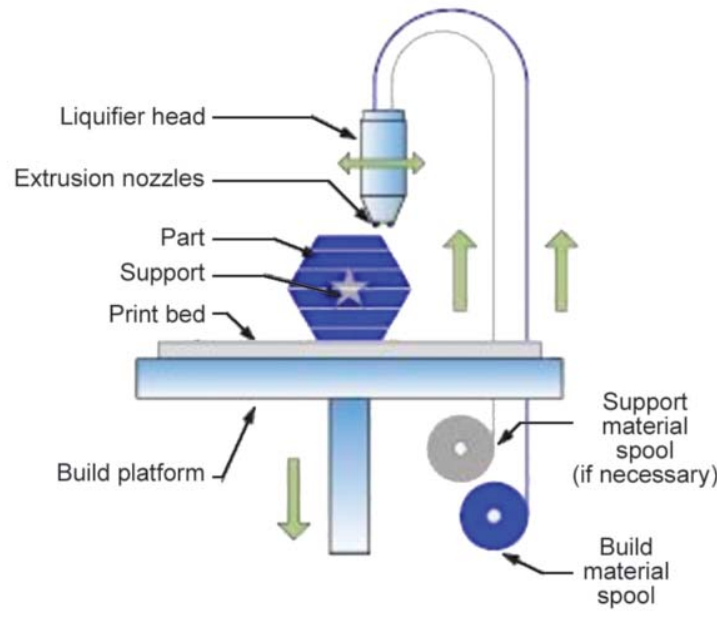

a)

Figure 4. (a) Schematic of the FDM technique. Reprinted from [75] with permission from Elsevier (b) FDM printer with a PLA filament (at the Federal Institute of Industrial Research Oshodi, Nigeria).

the mechanical strength of silk/polypropylene materials is greater than that of jute/polypropylene composites. Recent reports revealed that $3 \mathrm{D}$ printing had found great industrial applications, especially in biomedical engineering. In all likelihood, PLA/silk composite cannot be used to replace metals, but for bone fracture, it could be the perfect material. Steel plates have been a major medical tool, used by surgeons for fixing fractured bones. However, the challenge encountered in this has been that the steel blocks new bone cells from repairing the fracture [80].

In 2008, Professor Alan Lau's group at the Hong Kong Polytechnic University, combined silk fibres with PLA and found that the polymer became stronger and harder, which was credited to the increase the Young's modulus of the composite due to silk fibre incorporation. They additionally indicated that the material was able to retain its biodegradability and concluded its viability and potential as a tissue engineering material [6]. In orthopedic surgery, 3D printing was chiefly applied in the areas of anatomical models for diagnosis and surgical planning and customized implants and cast [81]. With the 3D printed model, the pre-operative circumstance of complex fractures is clearer to the surgeon. The model also furnishes the surgeons with the information required for effective pre-operative planning and realistic simulation. Furthermore, the 3D printing technique enables the production of patient-specific implant and cast that precisely matches the patient's body contour, for instance, the reconstruction of a range of bone fractures and pelvic bone resection [82].

Yeon et al. [74] were able to use 3D printed (silk/PLA filament) parts for the treatment of bone fracture without drilling a hole in the bone. Given their evaluation of the characteristics of each bone clip, they developed a PLA/Hydroxyapatite(HA)/silk composite bone clip, which showed similar mechanical property, but with superior biocompatibility when compared to PLA and PLA/HA clip and they concluded that the 3D printed part improved the regeneration capacity with high biocompatibility. Current research in this area was reported in an article titled 'A soft touch for mending broken bones' as found in the 2017 Swinburne Research Impact Magazine, where the team of Professor Alan Lau, who is now at Swinburne University of Technology, Australia is looking to creating surgical pins and cages from PLA/silk composite [80]. Future research is envisaged to encompass the fabrication of $3 \mathrm{D}$ printed PLA/silk implants and the necessary clinical trials of these parts. If successful, it could become a good substitute as medical implants in humans [83]. A summary of the various fabrication techniques for PLA/silkworm fibre biocomposites and their key property findings is presented in Table 1 . 
Table 1. Summary of various fabrication methods of PLA/silkworm silk composites and their key properties findings.

\begin{tabular}{|c|c|c|c|}
\hline PLA/silk fibre composites & Fabrication method & Key findings & Ref. \\
\hline PLA/silk fibre & Two step* & $\begin{array}{l}\text { Optimal fibre length and weight content selected for better properties are } 5 \mathrm{~mm} \\
\text { and } 5 \mathrm{wt} \% \text { respectively leading to a maximum hardness of } 19 \mathrm{HV} \text {. Increasing } \\
\text { fibre length and content led to poor mechanical properties. }\end{array}$ & {$[6]$} \\
\hline PLA $/ 5 \mathrm{wt} \%$ silk fibre & Two step* & $\begin{array}{l}\text { Melt compounding at } 180^{\circ} \mathrm{C} \text { and the injection mould and barrel temperatures } \\
\text { maintained at } 200 \text { and } 45^{\circ} \mathrm{C} \text { respectively. Maximum tensile strength of } \\
70.6 \mathrm{MPa} \text {. }\end{array}$ & {$[2]$} \\
\hline PLA/unidirectional silk fibre & $\begin{array}{l}\text { Compression mould- } \\
\text { ing }\end{array}$ & $\begin{array}{l}\text { Optimum compression temperature }\left(185-195^{\circ} \mathrm{C}\right) \text {. At high temperature, } \\
\text { strength decrease as silk fibres deteriorate and the melt resins flow out from } \\
\text { unidirectional composite due to the macroscopic flow of low viscosity resin. }\end{array}$ & [63] \\
\hline $\mathrm{PLA} / 5 \mathrm{wt} \%$ tussah silk & Two step* & $\begin{array}{l}\text { Elastic Modulus in the range of } 1.833-2.439 \mathrm{GPa} \text {. Strain and peak stress de- } \\
\text { creased from neat PLA to the reinforced sample with values of } 4.575 \% \text { and } \\
61.25 \mathrm{MPa} \text { respectively. }\end{array}$ & [39] \\
\hline $\mathrm{PLA} / 5 \mathrm{wt} \%$ tussah silk & Two step ${ }^{*}$ & $\begin{array}{l}\text { Fibres in chopped form of } 5 \mathrm{~mm} \text { average length to prevent coiling with screws } \\
\text { or plastic stretching during injection. Modulus ranges between } 3.21-4.08 \mathrm{GPa} \text {. } \\
\text { Tensile strength ( } 70.73 \mathrm{MPa} \text { ) and strain }(5.5 \%) \text { decreases by } 0.2 \text { and } 30 \% \text { re- } \\
\text { spectively from the neat PLA to the PLA/silk fibre composite sample }\end{array}$ & {$[87]$} \\
\hline PLA/waste silk laminate & $\begin{array}{l}\text { Hand-layup and fused } \\
\text { deposition modelling }\end{array}$ & $\begin{array}{l}\text { Waste silk fibre layers manually inserted in PLA and laminated structures are } \\
\text { 3D-printed. 2-laminates formed with infill density of } 20 \text { and raster angle of } \\
0 / 90^{\circ} \text {. Hand layup led to non-uniform inserts. Flexural peak strength (16.03- } \\
24.58 \mathrm{MPa}) \text { and Shore-D hardness }(68.83-79 \mathrm{HD})\end{array}$ & {$[64]$} \\
\hline PLA/silk/ hydroxyapatite & $3 \mathrm{D}$ printing & $\begin{array}{l}\text { Printed in form of bone clips of } 0.1 \mathrm{~mm} \text { layer thickness at } 170^{\circ} \mathrm{C} \text { nozzle tem- } \\
\text { perature and printing speed of } 20 \mathrm{~mm} / \mathrm{s} \text {. No significant effect of silk on com- } \\
\text { pressive strength of the composite as it was similar to the neat PLA. }\end{array}$ & [74] \\
\hline
\end{tabular}

${ }^{*}$ Two step refers to the melt compounding-injection moulding process

\section{Mechanical properties of PLA/silkworm silk fibre composites}

Over the years, certain polymers, e.g. poly(lactic acid) (PLA) have been designed to undergo controllable degradation as well as having the option to provide appropriate mechanical strength for implant applications. These polymers have been proposed in lieu of metals for orthopedic fixators, but their mechanical properties are inferior to bones $[6,84,85]$. Hence, there is a quest to improve these properties via reinforcing.

\subsection{Tensile properties}

The properties of the starting material (pristine PLA) during manufacture, usually play a crucial role in the final properties of the composite after fabrication. Cheng et al. [84] reported that when PLA is fabricated as a porous scaffold, its mechanical properties drop significantly and may not provide sufficient strength for load-bearing applications. Likewise, the pre-treatment of the silk fibre plays a role in the final mechanical properties of the composites part where it would be employed. As stated in the section on silk fibre preparation, degumming is a surface modification process, which allows a wide control of the silk fibre's properties, thus allowing their application in the production of novel bio-composites with unique/ specific mechanical properties. Suesat and Ujjin [86] investigated the effect of degumming conditions on the mechanical properties of PLA/silk blended fabrics. The fabric was designed with the silk yarn in the warp direction and PLA yarn in the weave direction. After initially treating the PLA and silk fabrics in a bath at varying degumming temperatures and $\mathrm{pH}$, they recommended a bath containing $10 \mathrm{~g} / 1$ Sera Wash (wetting agent) at $\mathrm{pH} 10$, liquor ratio of 20:1, and a temperature of $70^{\circ} \mathrm{C}$ for $15 \mathrm{~min}$ as the optimum conditions to prepare PLA and silk fibres to be used for the development PLA/silk blended fabric. Following the drying of the degummed composite fabric at room temperature, a measurement of the tensile strength and stiffness was performed. In each of the composite fabric tested, an improvement in tensile strength after degumming was evident. The density of each fabric also increased due to shrinkage, causing a more compact structure to be obtained. The authors also attributed the increase in stiffness to the improved density of the composite fabric.

Several researches have employed silk fibre as reinforcement to enhance PLA. Table 2 shows that silk fibres have better strength and modulus when compared with some selected natural fibres. Some of the findings of the use of silk fibre as reinforcement for PLA, gave better stiffness and ductility when compared to the pure PLA sample, but did not significantly improve the tensile strength [84]. Factors such as; the 
Table 2. Mechanical and physical characteristics of selected natural fibres.

\begin{tabular}{|l|c|c|c|c|c|}
\hline \multicolumn{1}{|c|}{ Fibre } & $\begin{array}{c}\text { Modulus } \\
{[\mathbf{G P a}]}\end{array}$ & $\begin{array}{c}\text { Strength } \\
{[\mathbf{M P a}]}\end{array}$ & $\begin{array}{c}\text { Density } \\
{\left[\mathbf{g} / \mathbf{c m}^{\mathbf{3}}\right]}\end{array}$ & $\begin{array}{c}\text { Elongation } \\
{[\mathbf{\%}]}\end{array}$ & References \\
\hline Bamboo & 35.9 & 441 & 0.80 & 9.5 & {$[120]$} \\
\hline Vetiver grass & $12.0-49.8$ & $247-723$ & 1.50 & 3.8 & {$[120]$} \\
\hline Coconut & $4.0-6.0$ & $131-175$ & 1.10 & 16.0 & {$[120]$} \\
\hline Silk & $9.4-22$ & $511-690$ & 1.17 & $1.5-2.5$ & {$[120,121]$} \\
\hline Coir & $4.0-6.0$ & $131-593$ & 1.2 & $15-40$ & {$[122,123]$} \\
\hline Jute & $10-30$ & $393-773$ & 1.3 & $1.16-1.8$ & {$[123,124]$} \\
\hline Hemp & 70 & 600 & 1.47 & $2.0-4.0$ & {$[125]$} \\
\hline Cotton & 12 & 400 & $1.5-1.6$ & $3.0-10.0$ & {$[124]$} \\
\hline
\end{tabular}

length of the fibre, weight content, fibre orientation, and fibre-matrix interface, have been reported by Cheung and coworkers $[6,85]$ to have influenced the mechanical properties of the resulting PLA/silk biocomposite.

The strength and stiffness of the composite, as an orthopedic fixator, is imperative because inadequate stiffness at the repair site can lead to gross motion and retardation of the bone healing process. The tensile strength and the percentage strain-at-break of the pure PLA samples were reported by Cheung and Lau [39] to be $\sim 65 \mathrm{MPa}$ and $\sim 4.7 \%$, respectively, while the $5 \mathrm{wt} \% \mathrm{PLA} /$ silk biocomposites recorded $\sim 61 \mathrm{MPa}$ and $\sim 4.6 \%$, respectively. This shows that the pure PLA sample has better ductility. The elastic modulus of the same weight of silk fibre in PLA was also reported to be $\sim 2.439 \mathrm{GPa}$, which was $\sim 33 \%$ $(1.833 \mathrm{GPa})$ higher than the pristine PLA. However, it is imperative also to consider the impact of the fibre length on these properties. Some researchers, Ho et al. [87] chopped the silk fibre into $5 \mathrm{~mm}$ length to avoid coiling with screws and extending the fibres plastically, during the injection process. The modulus was reported to have increased by over $27 \%$ with $5 \mathrm{~mm}$ silk fibre, but there was no increase in the tensile strength. This phenomenon was attributed to the disturbance of both inter and intra-bonding on the silk fibre with PLA, during the blending process. The investigation concluded that the use of silk fibre, as reinforcement, can improve the modulus of PLA as well as modify its pace of bio-degradability, which are significant properties for the design of implants for bone fixation.

In order to ascertain the optimal amount and length of silk fibre to be used to improve these properties, Cheung et al. [6] prepared a PLA/silk biocomposite by cutting the fibre into (between 3-6 $\mathrm{mm}$ ) and then mixed the fibre and PLA at various ratios of; 1:99, 3:97, 5:95 and 7:93. The sample with $5 \mathrm{~mm}$ fibre

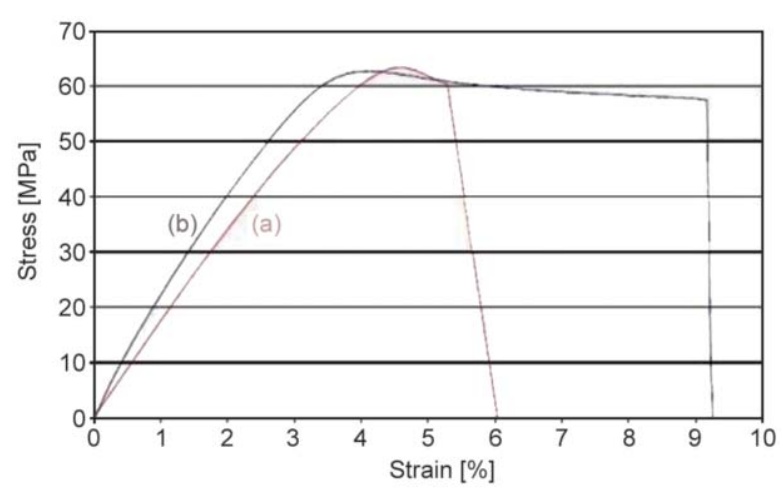

Figure 5. Stress-strain curves of (a) pure PLA sample and (b) $5 \mathrm{wt} \% \mathrm{PLA} /$ silk fibre biocomposite. Reprinted from [6], with permission from Elsevier.

length and $5 \mathrm{wt} \%$ of silk fibre showed interesting behavior. In spite of the fact that it did not improve the tensile strength, however, it increased the strain-atbreak by $53 \%$, as shown in Figure 5. When compared to the modulus reported by Cheung and Lau [39], the reinforced composite of $5 \mathrm{~mm}$ and $5 \mathrm{wt} \%$ improved by $4 \%$. This was attributed to the silk fibres acting as micro-pins inside the matrix, thereby generating an interlocking mechanism that prolonged the fracture process. This infers that the ductility of

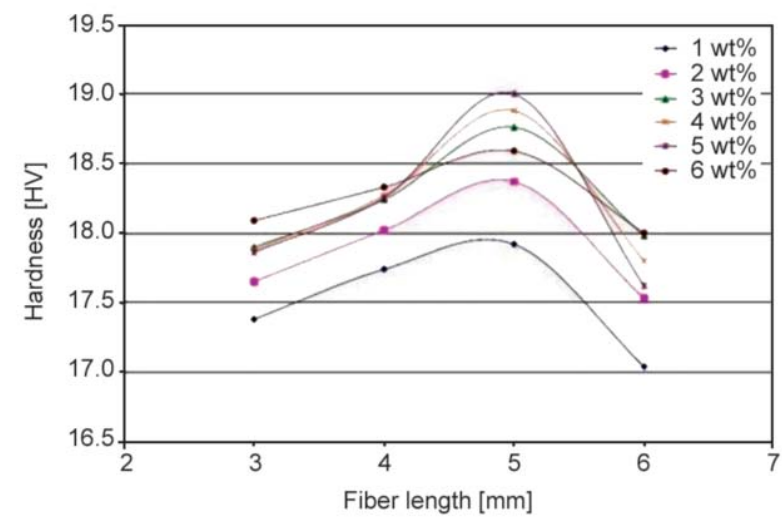

Figure 6. Micro-hardness test results on different fibre length and content of PLA/silk fibre biocomposites. Reprinted from [6], with permission from Elsevier. 
the silk fibre/ PLA biocomposite was higher than that of the pristine PLA.

\subsection{Micro-hardness indentation response}

The length and weight fraction of the fibre also play important roles on its hardness property. The hardness of pure PLA sample was reported to have increased by $\sim 12 \%$ after reinforcement with silk fibre [39]. It was also observed, as shown in Figure 6 that the hardness value increases for fibre length from 3 to $5 \mathrm{~mm}$, yet decreases beyond $5 \mathrm{~mm}$ for all biocomposite samples with various fibre weight contents (from 1 to $6 \mathrm{wt} \%$ ) [6]. It was observed from this work that the maximum viable measure of fibre weight content, needed to make the biocomposite was $6 \mathrm{wt} \%$ (Figure 6) because the trial to produce samples with $7 \mathrm{wt} \%$, resulted in a relatively brittle and hard to demould sample.

\subsection{Impact strength}

Ho [51] tested PLA and their composites samples and found the pristine PLA sample to be $\sim 156.3 \mathrm{~J} / \mathrm{m}$, higher than the average impact strength of the PLA/ $5 \mathrm{wt} \%$ silk composite, which was $110.7 \mathrm{~J} / \mathrm{m}$. The reduction of the impact strength was because silkworm silk fibres in the polymer matrix acted as stress

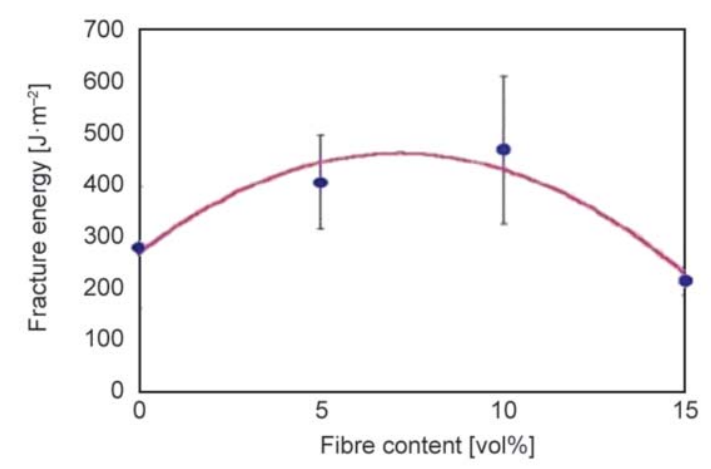

Figure 7. Fracture energy against fibre content of neat PLA specimen and $5-15$ vol\% PLA/silk fibre biocomposites [61]. concentrators, which decreased the crack initiation energy [51]. Similarly, Cheung et al. [61] reported an increment of $\sim 70 \%$ of both the fractured energy and energy loss, when $10 \mathrm{vol} \%$ of silk fibre (Figure 7) was added to the composite. However, a significant drop in the fracture energy was observed when more than 10 vol\% of silk fibre was added to the composite. This was attributed to the high volume percentage of fibre embedded in the matric, resulting in weak interfacial bonding. A summary of the mechanical properties of some reported PLA and their silk reinforced counterparts, is presented in Table 3.

The reviewed result demonstrates that fibre and matrix bonding is a significant factor required to obtain good mechanical properties. Therefore, there is a direct linkage between the strength of composites and the interfacial bonds, since the applied stress is more effectively transferred through the interface $[3,6]$. The decrease in the tensile strength of the composite in the work of Cheung et al. [6], can be traced to the weak bonding that exists between the fibre and the matrix. Further clarification was given by Ho et al. [87], stating that despite the mechanical interlocking, as a result of the fibre surface roughing, the hydrophilic natural silk fibre and the hydrophobic PLA matrix were not chemically bonded together. Due to this characteristic poor compatibility, the load transfer through the interface is constrained. Another factor contributing to the reduced strength can occur when the fibre breakage happens earlier than the failure of the surrounding [89].

\section{Thermo-mechanical and thermal properties of PLA/silkworm silk fibre composites}

\subsection{Dynamic mechanical response}

Dynamic mechanical analysis (DMA) is a procedure used to study the viscoelastic (elastic and viscous) responses of a sample under oscillating load against

Table 3. Summary of mechanical properties of pristine PLA and PLA/silk fibre biocomposites.

\begin{tabular}{|c|c|c|c|c|c|c|c|c|}
\hline \multirow{3}{*}{ Sample } & \multicolumn{7}{|c|}{ Properties } & \multirow{3}{*}{ References } \\
\hline & \multirow{2}{*}{$\begin{array}{c}\text { Hardness } \\
{[\mathrm{HV}]}\end{array}$} & \multicolumn{3}{|c|}{ Tensile properties } & \multicolumn{2}{|c|}{ Flexural properties } & \multirow{2}{*}{$\begin{array}{c}\text { Impact } \\
\text { strength } \\
{[\mathrm{J} / \mathrm{m}]}\end{array}$} & \\
\hline & & $\begin{array}{c}\text { UTS } \\
\text { [MPa] }\end{array}$ & $\begin{array}{c}\text { Elongation } \\
{[\%]}\end{array}$ & $\begin{array}{c}\text { Stiffness } \\
\text { [GPa] }\end{array}$ & $\begin{array}{c}\text { Flexural strength } \\
{[\mathrm{MPa}]}\end{array}$ & $\begin{array}{c}\text { Stiffness } \\
\text { [GPa] }\end{array}$ & & \\
\hline Pure PLA & 17 & 65.19 & 4.675 & 1.83 & - & - & - & \multirow{2}{*}[39]{} \\
\hline $5 \mathrm{wt} \%$ silk/PLA & 19 & 61.25 & 4.575 & 2.439 & - & - & - & \\
\hline Pure PLA & 17 & 65.19 & 6.73 & 3.75 & 107.37 & 3.58 & - & \multirow{2}{*}[6,90]{} \\
\hline $5 \mathrm{~mm} / 5 \mathrm{wt} \%$ silk/PLA & 19 & 62.08 & 10.29 & 4.99 & 71.71 & 4.01 & - & \\
\hline Pure PLA & - & 70.73 & 5.5 & 3.21 & 109.4 & 3.98 & - & \multirow{2}{*}[51,87,126]{} \\
\hline $5 \mathrm{wt} \%$ silk/PLA & - & 70.60 & 3.8 & 4.08 & 97.41 & 4.06 & - & \\
\hline
\end{tabular}


temperature, time or frequency, where the frequency of oscillation is proportional to the modulus of the material. The significant properties obtained during a DMA analysis, as a function of temperature are the storage modulus $\left(E^{\prime}\right)$, which refers to the energy stored in the sample elastically after the stress has been applied (associated with the elastic part of the material), and the loss modulus ( $\left.E^{\prime \prime}\right)$ which describes the energy dissipated during deformation (associated with the viscous part of the material). Another commonly used quantity is the damping coefficient $(\tan \delta)$ given as the ratio of the loss modulus to the storage modulus $\left(\tan \delta=E^{\prime \prime} / E^{\prime}\right)$, which is identified with material's capacity to dissipate energy in the form of heat $[41,85,90]$.

Ho [51] designed a PLA/silk composite for bone fixator, which requires high storage modulus $\left(E^{\prime}\right)$ and loss modulus $\left(E^{\prime \prime}\right)$ to enhance its ability to absorb and dissipate energy, respectively, in a pre-determined time, i.e. during an acceptable duration when the fixator is in the process of degradation. The result showed that the $E^{\prime}$ of the composite is higher than that of the pristine PLA. This was ascribed to the existence of silkworm silk fibre, which formed as physical cross-linkage and permitted stress transfer between the silkworm silk fibre and the PLA. A similar result was reported by Cheung and Lau [91], where the increase in storage modulus in PLA/silk was attributed to the effect of the fibre in the viscoelastic matrix, hence, allowing for the transfer of stress and reducing the mobility and deformation of the matrix. The high value of $\tan \delta$ implies that once the deformation is prompted, the material will not recover to its initial dimension. The decrease in $\tan \delta$ also signifies an improvement in the hysteresis of the system and a decrease in the internal friction [92]. At $37^{\circ} \mathrm{C}$,

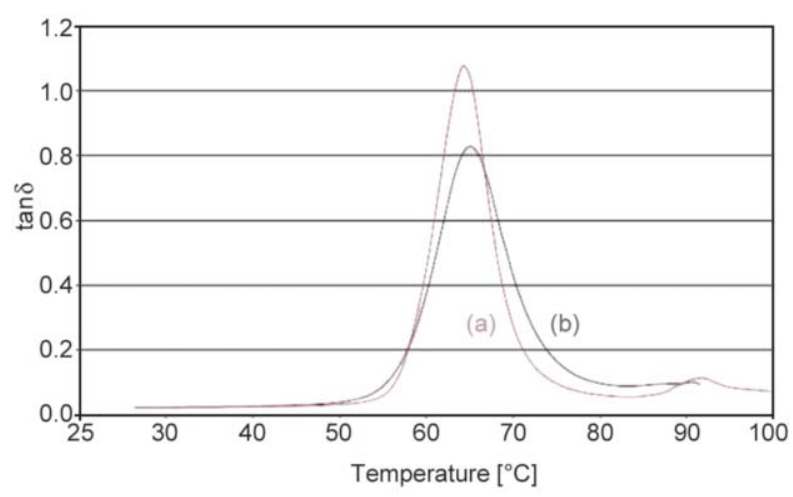

Figure 8. Tan $\delta$ as a function of the temperature of; (a) pure PLA sample and (b) $5 \mathrm{wt} \%$ PLA/silk biocomposite. Reprinted from [93], with permission from Elsevier. which is the normal human body temperature, there was no considerable contrast in $\tan \delta$ for both the composite and the pristine PLA, as shown in Figure 8.

\subsection{Crystallization and melting behaviour}

The differential scanning calorimetry (DSC), a versatile thermal analysis technique for polymer, is typically embraced to study the thermodynamic processes (glass transition, specific heat capacity) and kinetic events, such as cure and enthalpic relaxations that are related with physical aging or stress. In other words, it allows for the measurements of changes in the polymer thermal properties due to the alteration of temperature. Usually, polymers are not $100 \%$ crystalline materials, making them amorphous or semi-crystalline. Generally, the greater the crystallinity of a polymer the more noteworthy are its stiffness and density. The glass transition temperature $\left(T_{\mathrm{g}}\right)$ is the temperature where the polymer changes from a hard and relatively brittle state to a soft or rubbery state $[92,93]$. The $T_{\mathrm{g}}$ and the crystallinity of polymers have additional indirect effects on the degradation rates because degradation first occurs in the amorphous regions and later in the crystalline zones $[61,88]$. The $T_{\mathrm{g}}$ of PLA is above the physiological human body temperature of $37^{\circ} \mathrm{C}$; hence it is glassy in nature and can be applied to the biomedical domain. The $T_{\mathrm{g}}$ of pure PLA and PLA $/ 5 \mathrm{wt} \%$ silk composite was reported by Cheung [90] to be 60.2 and $64.4^{\circ} \mathrm{C}$ respectively, with an increment of $7 \%$ from the neat to the composite sample. However, a $14{ }^{\circ} \mathrm{C}$ drop in the crystallization temperature from $114{ }^{\circ} \mathrm{C}$ and a slight change in the melting temperature $\left(T_{\mathrm{m}}\right)$ of the PLA were experienced following the addition of $5 \mathrm{wt} \%$ silk fibres [90].

There are two fundamental factors that control the crystallization of the polymeric composite systems in relation to additives added to the composites. The first is related to the nucleating effect from the added additives, which result in an augmentation of crystallization temperature and a beneficial effect on the degree of crystallization. The second is the restriction of the migration and diffusion of polymer chains to the surface of the developing polymer crystal in the composite, thereby, leading to a reduction in the crystallization temperature $\left(T_{\mathrm{c}}\right)$ and hence, a negative impact on the degree of crystallization $[61,89]$. The latter was observed by Ho [51], where there was a reduction in crystallization temperature (by $\sim 4.68^{\circ} \mathrm{C}$ ) after the addition of the silk fibre, leading to an 
Table 4. Comparison of the thermal properties of pristine PLA and PLA/silk fibre biocomposites at different weight fraction proportions. Silk in wt $\%$.

\begin{tabular}{|c|c|c|c|c|c|c|c|}
\hline \multirow{2}{*}{ Sample } & $\begin{array}{c}\boldsymbol{T}_{\mathbf{g}} \\
{\left[{ }^{\circ} \mathbf{C}\right]}\end{array}$ & $\begin{array}{c}\boldsymbol{T}_{\mathbf{c}} \\
{\left[{ }^{\circ} \mathbf{C}\right]}\end{array}$ & $\begin{array}{c}\boldsymbol{T}_{\mathbf{m}} \\
{\left[{ }^{\circ} \mathbf{C}\right]}\end{array}$ & $\begin{array}{c}\Delta \boldsymbol{H}_{\mathbf{c}} \\
{[\mathbf{J} / \mathbf{g}]}\end{array}$ & $\begin{array}{c}\Delta \boldsymbol{H}_{\mathbf{m}} \\
{[\mathbf{J} / \mathbf{g}]}\end{array}$ & $\begin{array}{c}\boldsymbol{X} \\
{[\mathbf{\%}]}\end{array}$ & References \\
\hline \multirow{3}{*}{ Pure PLA } & 60.2 & 114.0 & 166.5 & 34.5 & 35.4 & 38.1 & {$[6,39]$} \\
\cline { 2 - 8 } & 53.7 & 94.86 & 163.44 & 29.46 & 48.0 & 51.2 & {$[51]$} \\
\cline { 2 - 8 } & 62.0 & 104.0 & 168.0 & & & & {$[95]$} \\
\hline PLA/silk (95/3) & 59.6 & 112.5 & 163.0 & 39.0 & 40.9 & - & {$[2]$} \\
\hline \multirow{3}{*}{ PLA/silk (95/5) } & 64.4 & 100.5 & 168.4 & 19.9 & 35.7 & 38.4 & {$[6,39]$} \\
\cline { 2 - 8 } & 59.6 & 111.2 & 162.3 & 48.8 & 48.4 & - & {$[2]$} \\
\cline { 2 - 8 } & 53.7 & 90.18 & 162.71 & 29.50 & 48.4 & 51.7 & {$[51]$} \\
\hline
\end{tabular}

$\Delta H_{\mathrm{c}}=$ crystallization enthalpy

$\Delta H_{\mathrm{m}}=$ measured melting enthalpy

increased rate of degradation. Over $3 \mathrm{wt} \%$ of silk fibre incorporation in PLA decreased the crystallization temperature, as reported by Zhao et al. [2] and the enthalpy of crystallization of all the PLA/silk composites was reported to be higher than the pristine PLA. The finding by Zhao et al. [2] demonstrates that the crystallization ability of PLA can be enhanced as a result of silk fibre addition, which may act as a nucleating agent. The molecular chemistry and chain structure play a major role in the degree of crystallinity $(X)$. This is because of the side-branches and cross-linking upset the mobility of chains. In addition, monomer units with complex species render crystalline order difficult [93]. Since these polymers are not $100 \%$ crystalline, it explains the degree of crystallization summarized in Table 4. Similar factors, such as; chain flexibility, molecular weight, branching/crosslinking, intermolecular attraction, and steric effects additionally influence the $T_{\mathrm{g}}[94,95]$.

\subsection{Thermal degradation}

Thermogravimetric analysis (TGA) is an effective methodology for evaluating the thermal stability of polymeric materials. In order to study the thermal stability, TGA provides information on the decomposition temperature $\left(T_{\mathrm{d}}\right)$ of the composite. This is important to know the thermal behavior and the changes the developed composite would experience in service. It is also a significant factor in the manufacturing and functioning of biodegradable and bioresorbable composite bone fixators because the material can experience volume or length variations, owing to changes in moisture content, curing, stress release and phase changes during heating $[51,96]$. Huda et al. [92] reported that the thermal degradation of PLA/recycled newspaper cellulose fibre (RNCF) composite occurred in three stages; majorly due to release of absorbed moisture in the fibres (40$\left.130^{\circ} \mathrm{C}\right)$, degradation of cellulosic substances $(195-$ $360^{\circ} \mathrm{C}$ ) and non-cellulosic materials $\left(360-469^{\circ} \mathrm{C}\right)$. However, reports from PLA/silk composite shows different behavior.

In the study by Zhao et al. [2], a major degradation was observed between $265-390^{\circ} \mathrm{C}$, which was the differential region between the composite and pristine PLA because no difference in thermal stability was observed before $265^{\circ} \mathrm{C}$. This result can be validated because silk fibre has been reported to undergo degradation between $250-350^{\circ} \mathrm{C}$ and then starts to decompose at $350^{\circ} \mathrm{C}$ [90]. Therefore, the degradation of the composite at the onset of the fibre degradation embedded in the matrix can be easily traced. The summary of the TG and Derivative Thermogravimetric (DTG) curves of PLA/silk composite studied by Zhao et al. [2] is presented in Table 5, indicating the different temperatures of weight loss with increasing silk fibre composition.

From the results (Table 5), it can be clearly observed that the values of all the PLA/silk composites are lower than the pristine PLA. This could be attributed to a reduced interaction between the silk fibre and

Table 5. TGA results of the neat PLA and PLA/silk fibre biocomposites [2]. Silk in wt\%.

\begin{tabular}{|l|c|c|c|c|}
\hline \multicolumn{1}{|c|}{ Sample } & $\begin{array}{c}\boldsymbol{T}_{\mathbf{P}} \\
{\left[{ }^{\circ} \mathbf{C}\right]}\end{array}$ & $\begin{array}{c}\boldsymbol{T}_{\mathbf{D}}^{\mathbf{i}} \\
{\left[{ }^{\circ} \mathbf{C}\right]}\end{array}$ & $\begin{array}{c}\boldsymbol{T}_{\mathbf{D}}^{\mathbf{0 . 5}} \\
{\left[{ }^{\circ} \mathbf{C}\right]}\end{array}$ & $\begin{array}{c}\boldsymbol{w t}_{\mathbf{g}}^{\mathbf{6 0 0}} \\
{[\mathbf{\%}]}\end{array}$ \\
\hline Neat PLA & 370.3 & 331.9 & 365.3 & 1.3 \\
\hline PLA/1 silk & 367.2 & 326.4 & 361.5 & 3.0 \\
\hline PLA/3 silk & 356.4 & 319.5 & 353.6 & 3.3 \\
\hline PLA/5 silk & 354.5 & 312.2 & 349.6 & 3.3 \\
\hline PLA/7 silk & 351.2 & 304.6 & 346.3 & 5.1 \\
\hline
\end{tabular}

${ }^{*} T_{\mathrm{P}}$ : $\quad$ The temperature at which there is the maximum of the DTG curves.

$T_{\mathrm{D}}^{\mathrm{i} .} \quad$ The temperature corresponds to $5 \%$ (initial) weight loss.

$T_{\mathrm{D}}^{0.5}: \quad$ The temperature at which $50 \%$ of the sample weight is lost. $w t_{\mathrm{g}}^{600}$ : Weight percentage of the residue at $600^{\circ} \mathrm{C}$. 
the PLA matrix as higher difference was observed with the inclusion of $7 \mathrm{wt} \%$ silk. However, Cheung [90] reported that the thermal stability of the PLA/silk biocomposite was improved with $5 \mathrm{~mm}$ length and $5 \mathrm{wt} \%$ of silk fibre. It was reported that the silk fibres act as obstacles for better heat insulation and decrease the permeation of the products of volatile degradation into the biocomposite. Generally, it is recommended that the use of silk fibres in a polymer matrix during fabrication processes or in an application, should be utilized below its minimum degradation temperature of $250^{\circ} \mathrm{C}$. This is because above this temperature, the property of the proposed composite would be significantly affected.

\section{Microstructural analysis of PLA/silkworm silk fibre composites in relation to biodegradation properties}

Fibre composites have quite a number of microstructural characteristics that are special, and when adequately documented, they can serve as a springboard for further development of these materials. The discussion on the microstructural observations as they relate to biodegradation properties of composite, is centered on the fibres, matrix and the fibre/matrix interfacial adhesion. As earlier mentioned, the demand for biodegradability, renewability, and recyclability of materials, especially natural fibres (because of their lightweight and cost) is growing amongst manufacturers and consumers. There is a paradigm shift towards 'greenness' and environmentally-friendly materials. The biodegradable and renewable characteristics of silkworm silk fibres are mainly important for the disposal of their components at end-of-life, thus, enabling the easy conversion of these materials into the production of thermal energy into thermal energy through combustion without leaving behind any residue [9]. The use of natural fibre, mixed with biodegradable polymers/matrix, e.g. PLA can produce composites that are biodegradable and environmentally-friendly. In this regard, the use of silkworm silk fibre as a form of reinforcement for fabricating PLA-based environmental biocomposites, have been reported [5,9].

PLA/silk fibres fall under the class of natural protein fibre as they are known to be biodegradable and crystalline, having structures that are well aligned, thereby making these fibres suitable potential materials for biomedical and bioengineering applications [39]. In the biomedical application of these materials, biodegradability is an important factor to reduce any extra discomfort the patients may experience as a result the removal of non-biodegradable implants after multiple surgeries. The biodegradability property of this fibre also ensures the smooth transfer of load from a damaging implant to neo-tissue. Biomaterials that slowly degrade also aids in sustaining the reliability of tissues in an implantation site, thus making the transfer of load-bearing burden to the regeneration of biologically functional tissues, easy [84].

Cheung et al. [84] carried out a biodegradable test on both samples of PLA and PLA/silk biocomposites in order to study the $\mathrm{pH}$ condition of the surrounding fluid. Twenty neat PLA samples and twenty PLA/silk fibre biocomposites were fabricated into dumb-bell shapes, and in-vitro biodegradation test was done by using Dulbecco's Phosphate Buffered Saline (PBS) at a temperature of $99^{\circ} \mathrm{F}\left(\sim 37.222^{\circ} \mathrm{C}\right)$ for $4,8,12$ and 16 weeks in a shaking incubator. The samples were monitored on a weekly basis by using a $\mathrm{pH}$ meter; the result showed that the $\mathrm{pH}$ value in the range between 7.37 and 7.41 was the same for both the pure PLA and the PLA/silk samples. This possibly indicates that degradation does not affect the $\mathrm{pH}$ values, hence points to the likelihood of biocompatibility and biodegradability of PLA and PLA/silk. It is pertinent to state that the control of the rate of biodegradation is also an important factor in ensuring that the structural integrity is maintained until loaded cells are able to acclimate to the environment before implants are eventually replaced by new tissues. The presence of silk fibre in the PLA matrix increases the mechanical properties, e.g. stiffness, thermal stability and considerably, improves the degradation capacity of the PLA matrix [2]. Thus, increasing the silk fibre content could cause stress shielding of the bone and consequently leading to bone loss [88]. The relationship between the silk content and degradation in the PLA matrix was found to be direct. Zhao et al. [2] investigated the biodegradable properties of PLA/silk. Enzymatic degradation tests were carried out on fabricated test samples, and changes in the surfaces of the samples were also examined by using the scanning electron microscope (SEM). Results as observed in Figure 9, showed that several pores were formed on the surface of the samples after degradation, and these pores were found to increase in diameter with incubation time, indicating a well-pronounced degradation.

From the biodegradation test, also conducted by Zhao et al. [2], the SEM micrographs in Figures 9, 


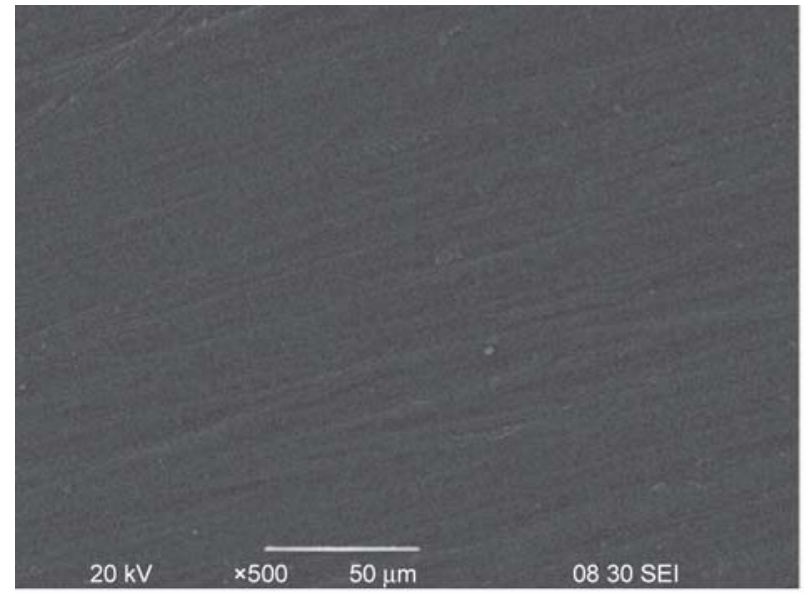

a)

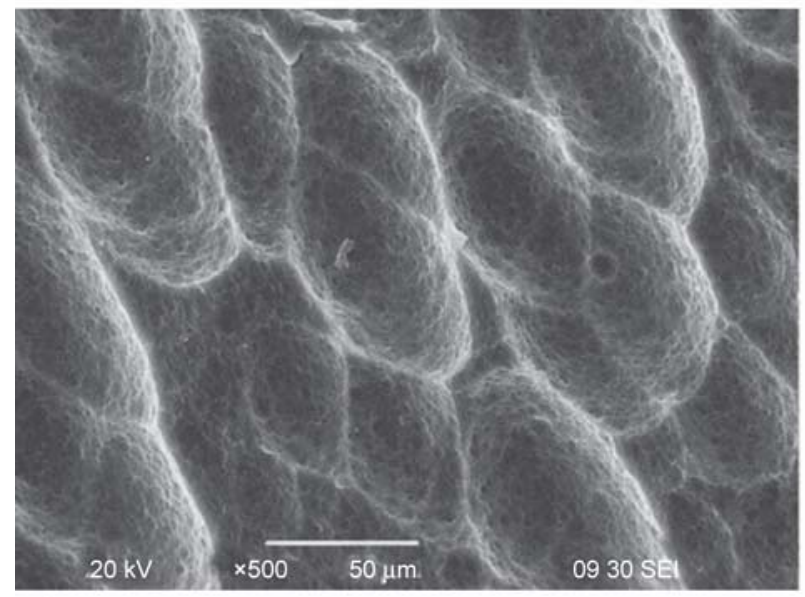

c)

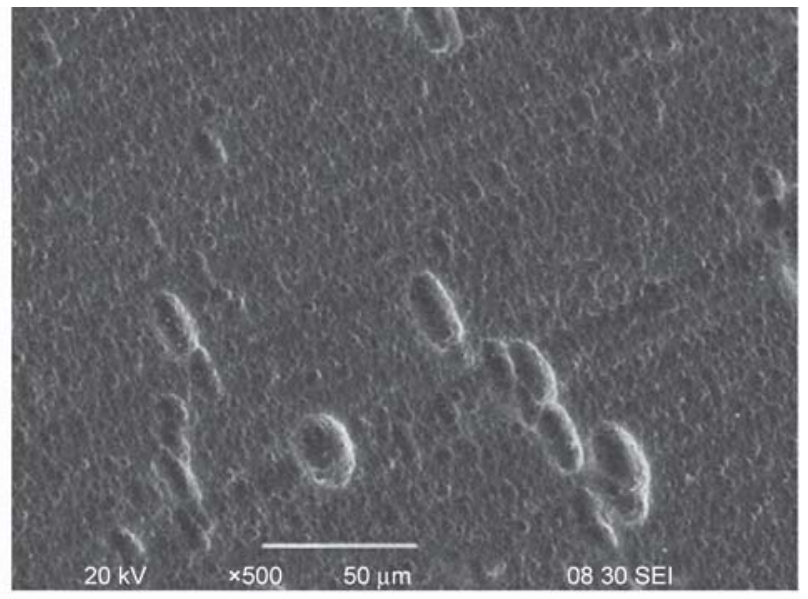

b)

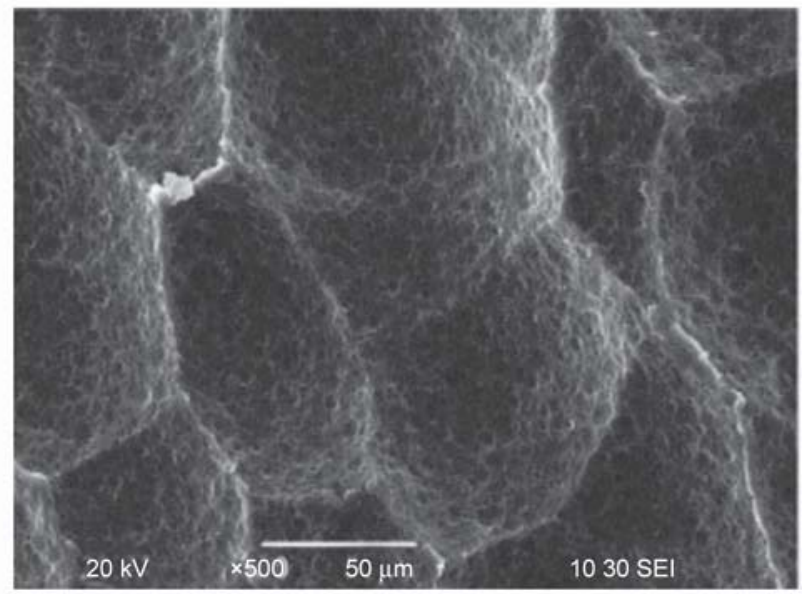

d)

Figure 9. Scanning electron micrograph of neat PLA after an incubation time of (a) 0 (b) 24 hrs (c) 72 hrs and (d) 120 hrs enzymatic degradation. Reprinted from [2], with permission from Elsevier.

10 and 11 , showed that there were changes in the surface of the composite after the enzymatic degradation test of the PLA/silk and PLA. Before degradation, the surface of the pristine PLA was seen to be smooth, but after degradation (at different times), there were appearances of pores and cavities, which increased in diameter as incubation time increased, hence, indicating further degradation. The surfaces of the PLA/silk composites for the different weight percents of silk fibre, showed rougher surfaces when compared with the neat PLA before degradation (Figure 9). The rougher fibres have been proven to increase the degradation process, a clear indication that the incorporation of more silk fibre to the PLA (increasing the fibre content), will accelerate the degradation process because more silk fibres will be exposed on the surface of the composites, prior to degradation. The enzymatic degradation, which leads to loss of weight is an important factor that can be used in the description of the degradability of a material. This happens as a result of a hydrolytic process, which takes place in both the surface of the composites and at the interfacial zone between the fibre and the matrix. There was no report on the delamination/debonding of the fibre from the matrix during the degradation process.

On the nature of the fracture surface, only the surface crack, along the silk fibre, was reported (as shown in Figure 10c with the sample containing $3 \mathrm{wt} \%$ fibre content and Figure $11 \mathrm{~b}$ with $7 \mathrm{wt} \%$ fibre content). Fracture surface characterization was carried out on pure PLA and PLA/silk biocomposite samples by Cheung et al. [84]. This was done at different times in order to examine the samples after the biodegradation test. The result showed that the fracture surface of both test samples before the biodegradation test was relatively rough, and no void was found when related to the fracture surfaces during the biodegradation test $[6,84]$.

Cheung et al. [6] also examined the fractured surface of the silk fibre/PLA biocomposite by using the SEM. The micrographs (Figure 12a) showed that pure PLA was smooth, and no void was found, indicating the 


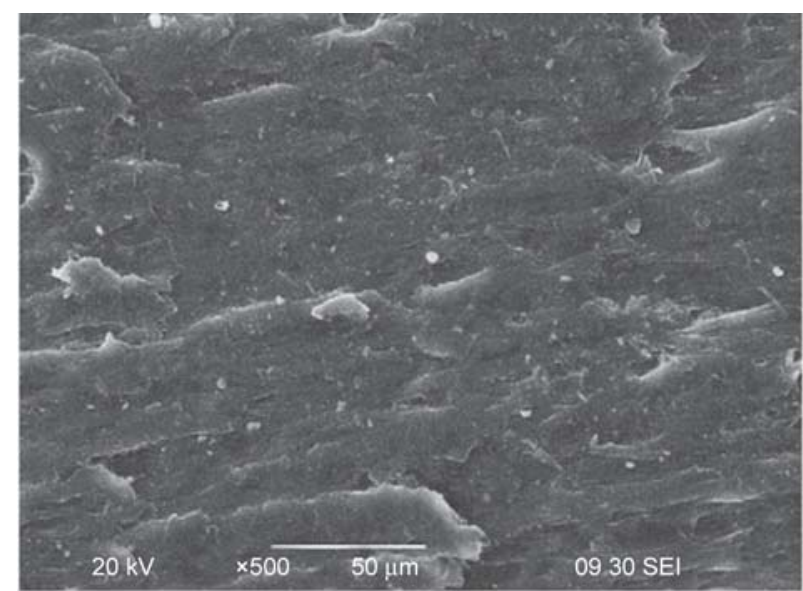

a)

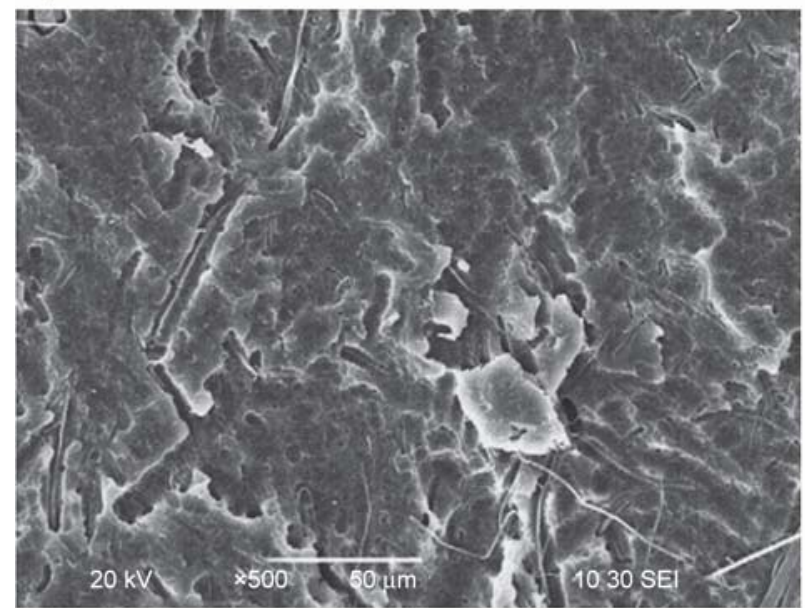

c)

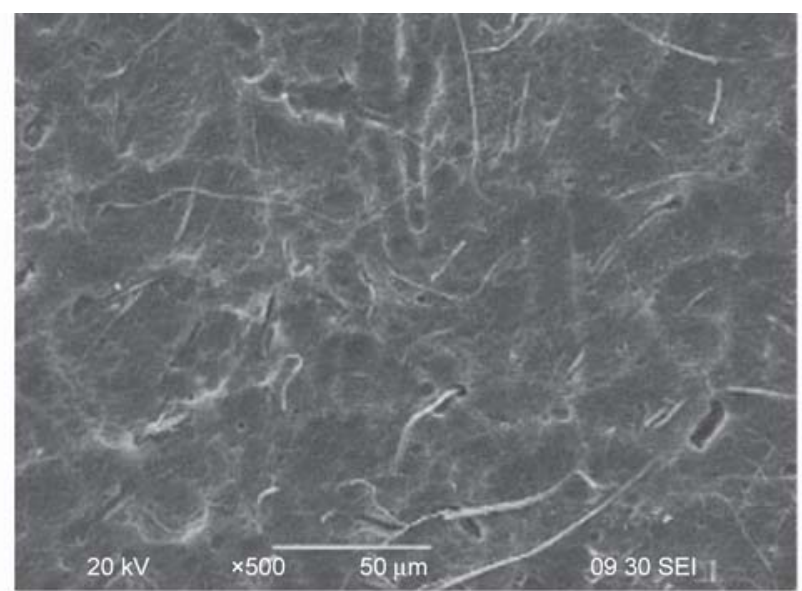

b)

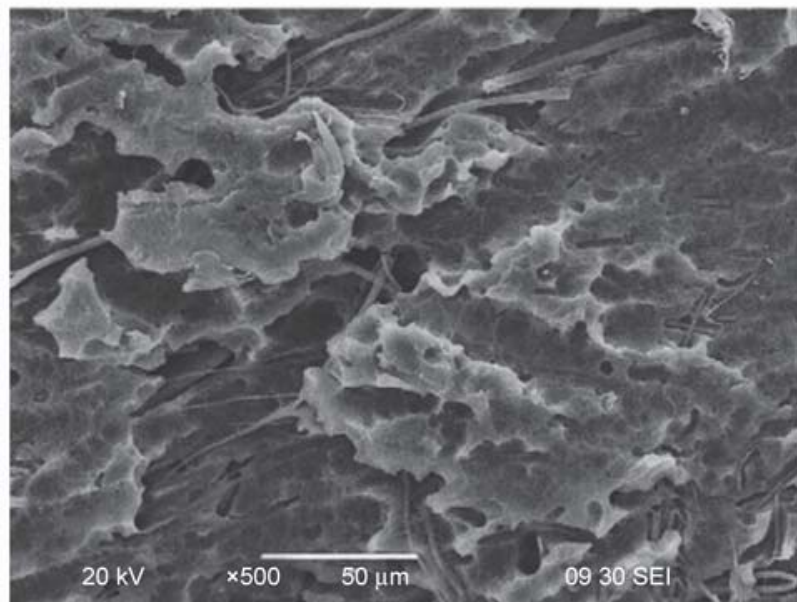

d)

Figure 10. Scanning electron micrograph of PLA/silk fibre biocomposite with $3 \mathrm{wt} \%$ respectively silk after an incubation time of (a) 0 (b) $24 \mathrm{hrs} \mathrm{(c)} 72 \mathrm{hrs}$ and (d) $120 \mathrm{hrs}$ enzymatic degradation. Reprinted from [2], with permission from Elsevier.

fact that there was no moisture absorption in the sample during manufacturing. Figure $12 \mathrm{~b}$ shows a good interfacial adhesion between the silk fibre and the PLA matrix, forming a network that is able to create some sort of reinforcement in the biocomposite during loading and also stopping crack propagation.

\section{Antibacterial properties of PLA/silkworm silk fibre composites}

Despite the unending quest of researchers for a paradigm shift from petroleum-based polymers to the greener types in the different fields of applications, the high susceptibility of some biopolymers such as PLA and silk fibre, to microbial attack questions the rationale behind this quest [100]. Microbial invasion of natural materials used for biomedical and food packaging applications and the consequent infections can be very chronic and at the worst terminal, especially for victims with a low level of neutrophils and immunocompromised body systems [100].
As PLA, silkworm silk fibres and their composites are extensively used for the foregoing applications; hence, this review considers it noteworthy to highlight the ongoing progress in this research territory. With reference to the literature data pool, very limited research findings are available on the antibacterial properties/activities of PLA/silk fibre composites. To date, only the work of Li et al. [101] is the most relevant reference (based on google scholar search) for the antibacterial activity of PLA/silk fibre composite. Although, the PLA/silk fibre composites used in their investigation contained nano-hydroxyapatite and silver nanoparticles. The in vitro antibacterial activity of the porous scaffold developed from the abovementioned materials was assessed against S.aureus and E.coli bacterial strains. Their result revealed that the developed scaffold was able to inhibit the growth of both bacterial strains [101]. Some interesting research findings are also available on the antimicrobial properties of PLA films functionalized with 


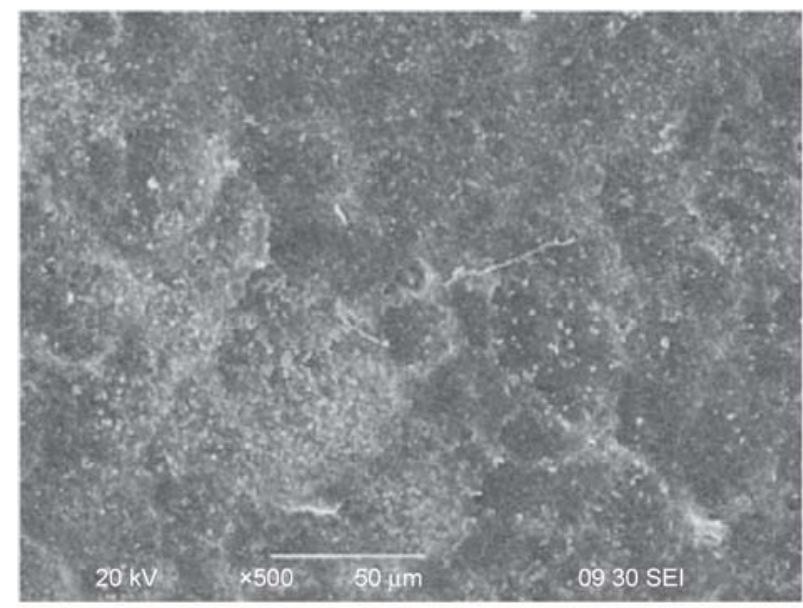

a)

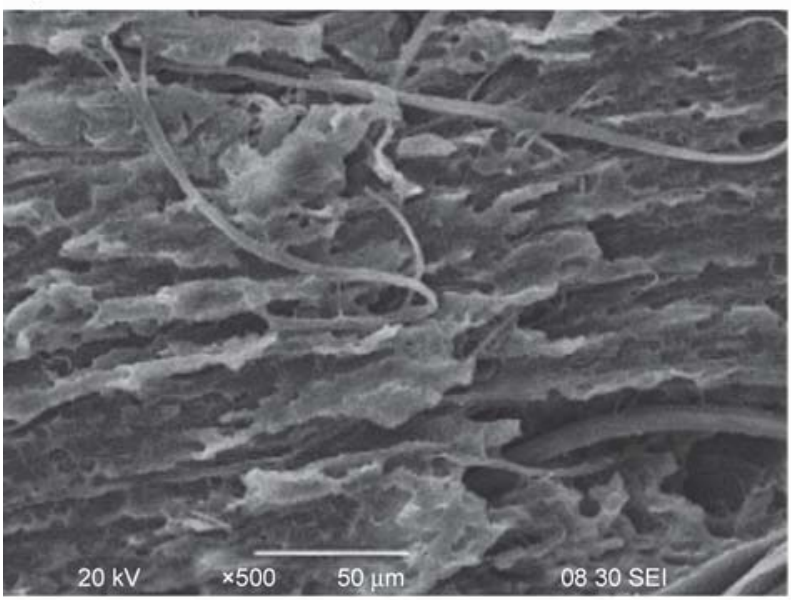

c)

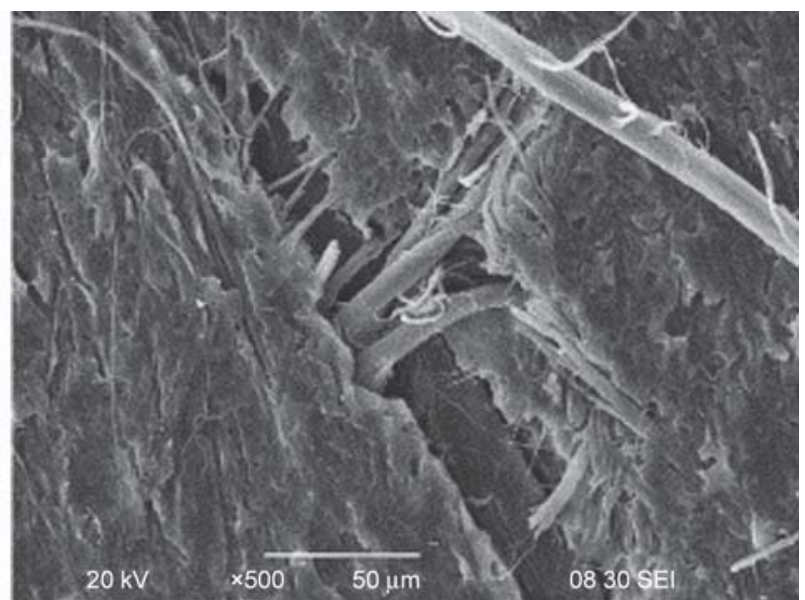

b)

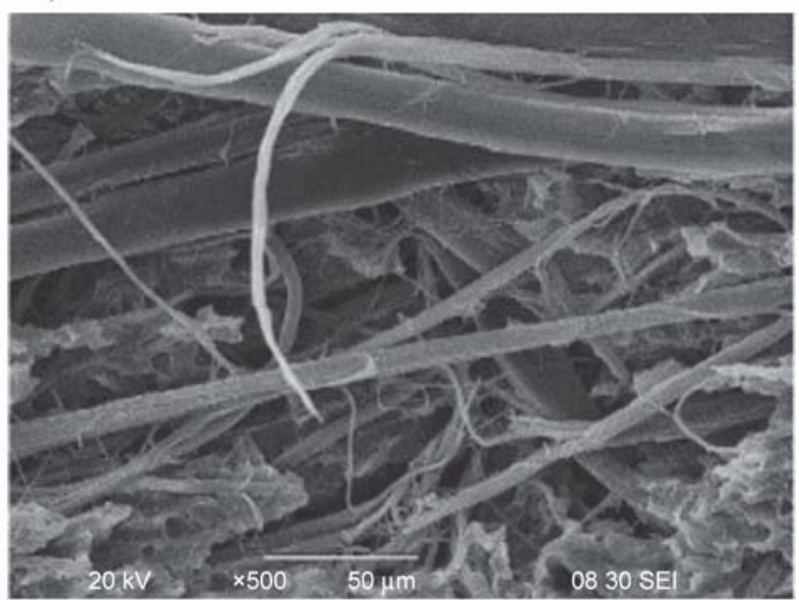

Figure 11. Scanning electron micrograph of PLA/silk fibre biocomposite with $7 \mathrm{wt} \%$ respectively silk after an incubation time of (a) 0 (b) $24 \mathrm{hrs} \mathrm{(c)} 72 \mathrm{hrs}$ and (d) $120 \mathrm{hrs}$ enzymatic degradation. Reprinted from [2], with permission from Elsevier.

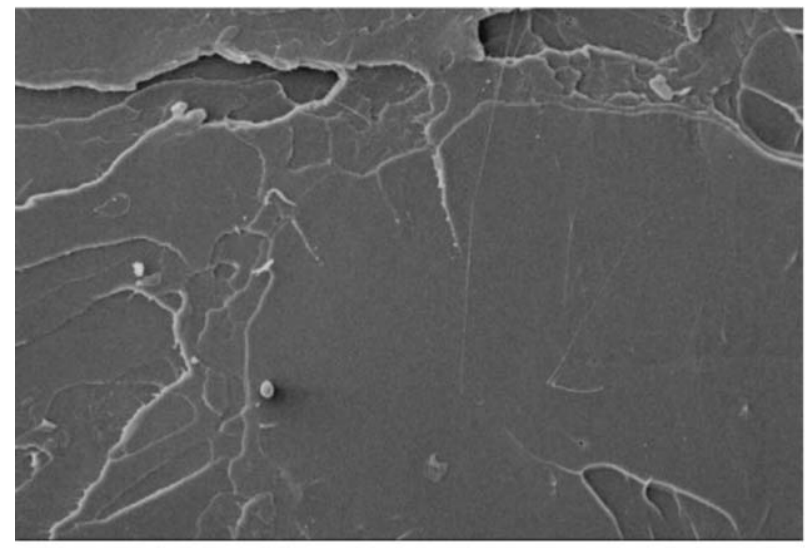

a)

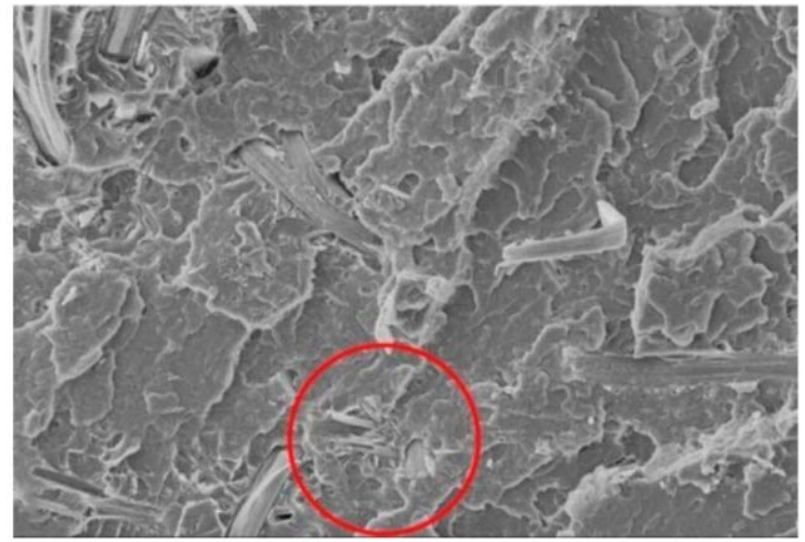

Figure 12. Scanning electron micrograph of (a) pure PLA and (b) PLA/silk fibre biocomposite fracture surfaces. Reprinted from [6], with permission from Elsevier.

chitosan, zinc oxide, glycerol and polyethylene glycol against the above-mentioned bacterial strains [100-102]. In the case of silk fibres, their antibacterial properties significantly improved by genetic modification [97] with functionalization with leaf extract [98], chitosan blending [99], silver nanoparticles
[100], gentamicin [101], tannic acid [102] and sericincopper [103]. Similarly, the resultant modified silk fibres showed strong bactericidal effects on S.aureus and E.coli.

From the above information, it is envisaged that the adaptation of the techniques used to confer 
antibacterial properties to PLA and silk fibres will yield the same results for PLA/silk fibre composites. Thus, biomaterials scientists, biomedical engineers and microbiologists with keen interest in the antimicrobial properties of the PLA/silk fibre composites are encouraged to consolidate their research efforts towards this area as the authors of the present work strongly believe it will be a remarkable expansion of the frontiers of existing knowledge on the preceding subject matter.

\section{Applications of PLA/silkworm silk fibre composites}

During the conceptual design phase of novel materials, it is expected that the materials scientist/engineer envisages solutions to particular problem or problems, reliant on the applications of the proposed materials, i.e. the primary goal of developing a new material should be inclined towards problem-solving activities. Interestingly, the development and characterization of PLA/silkworm-based materials have shown that these materials might be perfect candidates for solving some of the challenging problems, invariably encountered in the biomedical, textile and plastic industries $[61,64,84,86,96,104,105]$. The following section gives a succinct account of the recent progress that has been made in the last decade, regarding the applications of PLA/silkworm-based materials as effective solutions-provider in the abovementioned fields.

\subsection{An overview of PLA/silkworm silk fibre composites proposed for biomedical applications}

In tissue engineering and regenerative medicine, the issues of acceptable biocompatibility level and timedependent structural integrity of manmade biomaterials are of primary concern. Several attempts have been made by researchers to break this barrier. One of these attempts is the exploitation of PLA-silkworm-based materials for biomedical applications as they possess excellent biocompatible and bioresorbable properties that are desired of implantable biomaterials. In one study, Yin et al. [104] were able to develop PLA-silk fibroin-gelatin scaffold via electrospinning. After three months of subcutaneous implantation test, the developed composites were found to exhibit preferred porous structure, strong and pliable properties, capacity to support cell growth in-vitro and superb biocompatibility in-vivo [104].
These observations clearly translate to their confident suggestion of the developed materials as scaffolds for tissue engineering applications. In a conference report presented by Cheung et al. [61] at the European Conference on Composite Materials in Venice, Italy, these researchers documented improvement in the ductility, stiffness, and toughness of PLA composites reinforced with between 5-15 vol\% silkworm fibre. Hence, based on these findings and other positive results from their spectroscopic and microstructural characterizations, they proposed the composites developed for prosthetic applications [61].

A novel insight into the dynamic mechanical performance and thermal degradation of PLA-silk fibre composites, in line with their potential applications as scaffolds and implants, has been reported by Ho et al. [40]. In their work, they found that silk fibre can improve the mechanical integrity of PLA for the above-mentioned biomedical applications. However, appreciable research effort is needed to make the materials suitable for a thermomechanical-based biomedical application [40]. Another work by Ho et al. [96] investigated the in-vitro biodegradation of PLA/ silk fibre composites for 16 weeks. A mild acidity of the degradation material was observed for the composites. Both the degradation rate and mechanical properties (stiffness and ductility) of the composites were also found to improve with the addition of silk fibre to PLA. From their observations, they concluded that the regeneration duration of neo-tissues at the implantation site could be successfully controlled by reinforcing PLA with silkworm fibres [84]. Similarly, Mangat et al. [64] proposed PLA/silk composites for scaffolds development. This resulted from their positive findings, which revealed enhancements in the flexural strength, hardness, as well as biodegradation and antibacterial properties of porous biodegradable PLA/silk laminates.

In summary, it is evident that the last decade has experienced a rise in the interest of researchers in the synthesis and biomedical applications of PLA-silk composites. However, it is noteworthy to mention that most of the previous studies did not go beyond the proposition of their developed PLA-silk composites as promising materials for biomedical applications. One prominent exception to this was the bold step taken by Professor Alan Lau and his team at Swinburne University of Technology, to create surgical pins and cages from PLA-silk composites [80]. This was inspired by the significant enhancement of PLA's 
elastic modulus from 3.21 to $4.08 \mathrm{GPa}$, following the addition of silk fibres to PLA. In addition, the resultant composite retained its biodegradability [6]. Further research inputs are still needed to promote the clinical trials for successful in-vivo biomedical applications of PLA-silk composites.

\subsection{An overview of PLA/silkworm silk composites proposed for textile applications}

In the textile industry, customer's satisfaction is very crucial, which in turn makes the textile market highly competitive since customers must always be provided with multiple choices. Thus, it is mandatory for textile manufacturers to present outstanding fabrics in terms of texture, aesthetics, affordability, comfortability, re-usability, durability and in recent times, their environmental friendliness. Judging by recent research findings, PLA-silk blend seems to exhibit most of the above-mentioned desirable properties $[86,105,106]$. On the one hand, popularity is a hallmark of pure silk fabric in the textile industry. This is attributed to its shining appearance, soft texture, superb draping quality, washability, good tensile strength and appreciable resistance to abrasion [86, 106]. However, its high cost, coupled with its high susceptibility to pollution, wrinkles, and discoloration, has called for research attention. On the other hand, the eco-friendliness, sustainability, inexpensiveness and other attractive characteristics of PLA can be conferred to silk fabric in order to compensate for its foregoing deficiencies to meet modern-day textile applications [86, 105, 106]. Interestingly, pertinent researches on this subject matter have begun to emerge. Zhu and Pan [105] studied the properties of PLA/silk mixed fabrics. They found that the mixed fabrics exhibited better wearability, anti-pilling resistance and gas permeability than the pure silk fabric. Based on these findings, they confidently suggested mixed fabrics for textile application [105].

Suesat and Ujjin [86] reported that PLA-silk blend could successfully undergo the degumming process needed for silk pre-treatment to remove sericin at an elevated temperature of $70^{\circ} \mathrm{C}$ and a $\mathrm{pH}$ of 10 and a $\mathrm{pH}$ of 10 . Thus, the process has no negative effect on the structure and mechanical integrity of the fabric. They encouraged the industrial production of this blend for textile applications. Feng et al. [106] have also investigated the wearable performance of PHA/ PLA fibre/spun silk blended fabrics. Their results revealed that while the pilling resistance of the blended fabrics improved with weft density, the wrinkle recovery performance, air permeability and moisture permeability of the blended fabrics were not enhanced. Making reference to previous studies $[86,105,106]$, this is a clear indication that PLAsilk fabrics exhibit better textile properties than PHA/PLA/silk fabrics. Thus, further investigations are recommended to improve the textile applications of PLA-silk blend/composites.

\subsection{An overview of the prospects of PLA/silkworm silk fibre composites as promising materials for disposable/edible food packaging applications (DFPAs/EFPAs)}

Food packaging is a dynamic and an integral part of the food production line, where different types of materials, such as; papers, polymers (plastics, bioplastics and bio-based plastics), metals, glasses, and leaves are currently being employed as packaging materials, based on the types and properties of the food to be packaged [107]. Due to their low cost, lightweight, associated packaging aesthetics and relatively high compatibility with most food products, papers and polymers are typically the most widely used food packaging materials [108]. However, considerable emphasis is placed on polymers in this work in order not to digress from the key concept of the present review. According to the United States of America Food and Drug Administration, plastics are recognized as 'indirect food additives'. Therefore, they must conform to the requirements stated in Title 21 of the Code of Federal Regulations for food packaging applications [109]. As a matter of fact, to ascertain guaranteed preservation, containment and protection of food, a fundamental understanding of the properties of any material to be used as a disposable food packaging material is essential [110].

To date, synthetic/petroleum-based plastics such as; polyethylene, polystyrene, polypropylene and nylon are still dominating the market as food packaging materials. However environmental issues concerning their disposal, which contribute a large percentage to municipal solid wastes, has called for a rethink [111]. Although these materials have stood the test of time with reference to desirable properties (chemical resistance, microbial resistance, moisture impermeability, gas barrier property, abrasion resistance, mechanical performance, thermal stability, etc.) and 
field-proven reliability required of standard food packaging materials. However, there is still rising demand for a paradigm shift to disposable bioplastics and bio-based plastics that are biodegradable, compostable and edible, while maintaining the abovementioned qualities [112]. This proposition is considered to be highly far-reaching and tremendously beneficial to global environmental welfare and the sustainability of the food supply chain $[112,113]$. Interestingly, research findings have revealed PLA bioplastic and silk fibre biopolymer, combined with other materials, as suitable materials for DFPAs.

Previous studies have shown PLA to be the most commercially exploitable biopolymer for DFPAs. More so, it is easy to modify its physical and mechanical properties by simply changing its chemical composition and processing conditions $[100,114$, 115]. Different investigations on PLA films have revealed that these films are very suitable for DFPAs because, in addition to the fact that they are biodegradable, transparent, compostable, and produced from renewable resources, they exhibit the same behavior that is comparable to the mechanical, thermal, and barrier properties of most used synthetic polymers such as polystyrene and polyethylene [99]. However, the major drawbacks currently hindering their longterm deployment as materials for DFPAs in the food packaging industries include their low resistance to thermal stress, low stiffness, high water vapour transmission rate and high oxygen permeability [116]. Detailed and impressive information on the applications, delimitations, and suggestions for improvement of PLA and PLA-based materials for DFPAs can be found in the works of Öz et al. [117], Siracusa et al. [118], and Tawakkal et al. [110]. On the other hand, in a quest to curb the huge waste of perishable foods and its associated loss of economic values and resources, as reported by the Food and Agricultural Organization of the United Nations, new investigations into the suitability and efficiency of silk fibroin as edible food packaging materials (EFPMs), have begun to emerge [115]. Marelli et al. [115] conducted an experiment, wherein they used water-based processed silk fibroin as edible coatings for the preservation of strawberry and banana fruits. From their results, they found out that micrometer-thin silk fibroin membranes around the fruits, enhanced the fruits' shelf life at ambient conditions. They attributed this occurrence to the silk fibroin-induced phenomenon, which reduced cell respiration rate and water evaporation. Although limited to the knowledge of the authors of the present review, based on open literature search, to date, there exists no record of PLA/silk fibre/fibroin composites developed for DFPA and/or Edible Food Packaging Applications (EFPAs). Thus, researchers are strongly encouraged to explore this untapped avenue for novel and innovative ideas with great prospects that can facilitate the postharvest treatments of foods and equally promote their sustainable and bio-friendly packaging. In addition, the fact that silk fibres are readily biodegradable and compostable translates to their plausible ability to confer these properties to PLA/silk fibre composites, with reference to DPFAs and EFPAs specifications.

\section{Challenges and suggested solutions}

Manufacturing challenges are encountered in the development of these composites, particularly with the pristine constituents. In order to fabricate them by using large scale operations, such as injection moulding and extrusion, the polymer matrix must possess sufficient thermal stability, needed to prevent degradation and maintain appropriate molecular weight, and properties needed for good performance while in use [41]. PLA matrix still suffers some thermal degradation at certain processing temperatures due to its chemistry, rheology and physical properties. When PLA is in the filament form to be 3D-printed, it experiences shape deformation due to high-temperature exposure [119]. Likewise, there have been reports on certain the disadvantages by using PLA/silk filament in 3D printing, such as: low heat resistance, low glass transition temperature, and softening at elevated temperatures [119]. On that note, research on physical, thermal and rheological properties improvements of pristine materials or feedstock, such as PLA and PLA/silk filament would be apt.

Despite the reports of silk fibres enhancing some mechanical and thermal properties of PLA/silk composite, there are still more grounds to conquer in order to ensure the increased utilization of the composite in other applications that do not restrict it as a biocomposite. This is because, composite application or the means/routes of fabrication, has been limited to temperatures below $250{ }^{\circ} \mathrm{C}$ and in addition, the composites still exhibit a relatively low tensile strength, needed for its usage in some other applications. Major progress envisaged to further develop PLA/silk composite, would be to improve 
the degradation temperature and strength, thereby providing a wider range of applications.

Without a doubt, PLA/silk-materials are excellent biodegradable, sustainable, lightweight and green materials with great prospects and potentials for biomedical and textile applications. Although their biomedical applications are yet to pass clinical trials, it is predicted that in the near future, their use for invivo biomedical applications in tissue/cellular engineering and regenerative medicine, would transit from an embryonic phase to common practice. In addition, it is somewhat puzzling that the above-mentioned attractive properties of these materials have not been notably exploited for Disposable/Edible Food Packaging Applications (DFPAs/EFPAs). Thus, researchers are tremendously enjoined and equally encouraged to beam their searchlight in this direction. Such involvement will reduce the environmental pollution and carbon footprint, constituted by synthetic polymers, e.g., the polyolefins that are currently and extensively used for packaging applications. Moreover, both PLA and silk have been singularly and successfully combined with other materials for DFPAs. This is a clear indication that their combination with each other will result in a reliable, lowcost and green material for DFPAs. In addition, more and concerted research effort is currently needed to significantly improve the antibacterial properties of PLA/silkworm silk fibre composites against different bacterial strains. This will likely mitigate the invasion of the service environments where the composites have potential applications. Significant much emphasis should be concentrated on in-vivo environment due to its liable nature.

\section{Conclusions}

The development of natural fibre reinforced composites continues to attract considerable attention due to its role in promoting sustainable materials development. On that note, the progress made in research and development efforts of PLA/silkworm silk fibre composite has been considered in the current review, keeping in mind the United Nations sustainable development goals (SDGs) in developing advanced materials with good service performance and minimal impact on the environment. Their fabrication routes, including the transformative additive manufacturing approach, were discussed. Prior to that, effective and environmentally-benign fibre treatment strategies were considered. The mechanical, thermal and biodegradation properties of this composite were also compared with neat PLA in a bid to assess the reinforcing effect of silk fibres. Reviewed results and data indicated that silk reinforced PLA composites fared better. In addition, the structureproperty relationships were brought to light by microstructural evidences, which revealed all forms of defects arising from processing routes and parameters employed. An overview of the process steps for the development of PLA/silkworm silk fibre biocomposites, right from processing to the application areas, is presented in Figure 13.

The review further contains an overview of some specific application fields of this material, via textile,

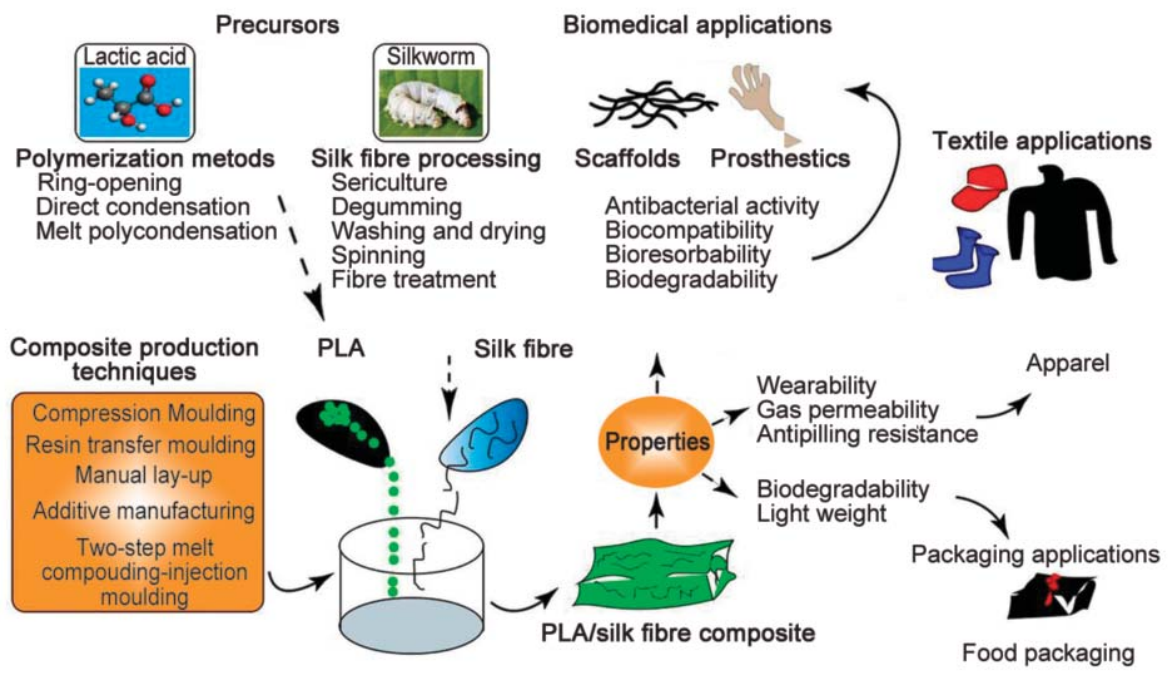

Figure 13. Graphical overview of the development, properties, and nascent applications of PLA/silkworm silk fibre biocomposites. 
food packaging applications (DFPAs/EFPAs), and biomedical, looking into its current state of the application in the biomedical context, where further development of surgical pins, made from 3D printed PLA/silk fibre composites, and implementation of clinical trials are upon us. Challenges faced in the advancement of this material and possible solutions were proffered. If such solutions are adopted and researched upon, the large scale application of this material in areas, such as DFPAs and EFPAs could be achieved.

\section{Funding source}

This research did not receive any specific grant from funding agencies in the public, commercial, or not-for-profit sectors.

\section{References}

[1] Fogorasi M. S., Barbu I.: The potential of natural fibres for automotive sector - Review. IOP Conference Series: Materials Science and Engineering, 252, 012044/1-012044/10 (2017). https://doi.org/10.1088/1757-899X/252/1/012044

[2] Zhao Y-Q., Cheung H-Y., Lau K-T., Xu C-L., Zhao D-D., Li H-L.: Silkworm silk/poly(lactic acid) biocomposites: Dynamic mechanical, thermal and biodegradable properties. Polymer Degradation and Stability, 95, 1978-1987 (2010). https://doi.org/10.1016/j.polymdegradstab.2010.07.015

[3] Cheng S., Lau K-T., Liu T., Zhao Y., Lam P-M., Yin Y.: Mechanical and thermal properties of chicken feather fiber/PLA green composites. Composites Part B: Engineering, 40, 650-654 (2009) https://doi.org/10.1016/j.compositesb.2009.04.011

[4] Conzatti L., Giunco F., Stagnaro P., Patrucco A., Marano C., Rink M., Marsano E.: Composites based on polypropylene and short wool fibres. Composites Part A: Applied Science and Manufacturing, 47, 165-171 (2013). https://doi.org/10.1016/j.compositesa.2013.01.002

[5] Cheung H-Y., Ho M-P., Lau K-T., Cardona F., Hui D.: Natural fibre-reinforced composites for bioengineering and environmental engineering applications. Composites Part B: Engineering, 40, 655-663 (2009). https://doi.org/10.1016/j.compositesb.2009.04.014

[6] Cheung H-Y., Lau K-T., Tao X-M., Hui D.: A potential material for tissue engineering: Silkworm silk/PLA biocomposite. Composites Part B: Engineering, 39, 1026-1033 (2008). https://doi.org/10.1016/j.compositesb.2007.11.009

[7] Melke J., Midha S., Ghosh S., Ito K., Hofmann S.: Silk fibroin as biomaterial for bone tissue engineering. Acta Biomaterialia, B, 1-16 (2016). https://doi.org/10.1016/j.actbio.2015.09.005
[8] Teimouri A., Azadi M., Emadi R., Lari J., Chermahini A. N.: Preparation, characterization, degradation and biocompatibility of different silk fibroin based composite scaffolds prepared by freeze-drying method for tissue engineering application. Polymer Degradation and Stability, 121, 18-29 (2015).

https://doi.org/10.1016/j.polymdegradstab.2015.08.004

[9] Ude A. U., Eshkoor R. A., Zulkifili R., Ariffin A. K., Dzuraidah A. W., Azhari C. H.: Bombyx mori silk fibre and its composite: A review of contemporary developments. Materials and Design, 57, 298-305 (2014). https://doi.org/10.1016/j.matdes.2013.12.052

[10] Altman G. H., Diaz F., Jakuba C., Calabro T., Horan R. L., Chen J., Lu H., Richmond J., Kaplan D. L.: Silkbased biomaterials. Biomaterials, 23, 401-416 (2003). https://doi.org/10.1016/S0142-9612(02)00353-8

[11] Ho M-P., Wang H., Lau K-T.: Effect of degumming time on silkworm silk fibre for biodegradable polymer composites. Applied Surface Science, 258, 3948-3955 (2012). https://doi.org/10.1016/j.apsusc.2011.12.068

[12] Ranakoti L., Gupta M. K., Rakesh P. K.: Silk and silkbased composites: Opportunities and challenges. in 'Processing of green composites. Materials horizons: From nature to nanomaterials' (eds.: Rakesh P., Singh I.) Springer, Singapore, 91-106 (2019). https://doi.org/10.1007/978-981-13-6019-0_7

[13] Ho M-P., Wang H., Lau K-T., Lee J-H., Hui D.: Interfacial bonding and degumming effects on silk fibre/ polymer biocomposites. Composites Part B: Engineering, 43, 2801-2812 (2012).

https://doi.org/10.1016/j.compositesb.2012.04.042

[14] Karthik T., Rathinamoorthy R.: Sustainable silk production. In 'Sustainable Fibres and Textiles'. (ed.: Muthu S. S.) Woodhead publishing, Cambridge, 1, 135-170 (2017).

[15] Fakirov S., Bhattacharyya D.: Handbook of engineering biopolymers. Homopolymers, blends, and composites. Hanser, Munich (2015). https://doi.org/10.3139/9783446442504

[16] Ikada Y., Tsuji H.: Biodegradable polyesters for medical and ecological applications. Macromolecular Rapid Communications, 21, 117-132 (2000).

https://doi.org/10.1002/(SICI)15213927(20000201)21:3<117::AID-MARC117>3.0.CO;2-X

[17] Mahmoodi N. M., Arami M., Mazaheri F., Rahimi S.: Degradation of sericin (degumming) of Persian silk by ultrasound and enzymes as a cleaner and environmentally friendly process. Journal of Cleaner Production, 18, 146-151 (2010). https://doi.org/10.1016/j.jclepro.2009.10.003

[18] Pérez-Rigueiro J., Viney C., Llorca J., Elices M.: Mechanical properties of single-brin silkworm silk. Journal of Applied Polymer Science, 75, 1270-1277 (2000). https://doi.org/10.1002/(SICI)1097$\underline{4628(20000307) 75: 10<1270:: A I D-A P P 8>3.0 . C O ; 2-C}$ 
[19] Pérez-Rigueiro J., Elices M., Llorca J., Viney C.: Effect of degumming on the tensile properties of silkworm (Bombyx mori) silk fiber. Journal of Applied Polymer Science, 84, 1431-1437 (2002).

https://doi.org/10.1002/app.10366

[20] Pérez-Rigueiro J., Viney C., Llorca J., Elices M.: Silkworm silk as an engineering material. Journal of Applied Polymer Science, 70, 2439-2447 (2002).

https://doi.org/10.1002/(SICI)10974628(19981219)70:12<2439::AID-APP16>3.0.CO;2-J

[21] Vroman I., Tighzert L.: Biodegradable polymers. Materials, 2, 307-344 (2009). https://doi.org/10.3390/ma2020307

[22] Kunduru K. R., Basu A., Domb A. J.: Biodegradable polymers: Medical applications. Encyclopedia of Polymer Science and Technology, 2, 263-285 (2016). https://doi.org/10.1002/0471440264.pst027.pub2

[23] Pang X., Zhuang X., Tang Z., Chen X.: Polylactic acid (PLA): Research, development and industrialization. Biotechnology Journal, 5, 1125-1136 (2010). https://doi.org/10.1002/biot.201000135

[24] Garlotta D.: A literature review of poly(lactic acid). Journal of Polymers and the Environment, 9, 63-84 (2001). https://doi.org/10.1023/A:1020200822435

[25] Lasprilla A. J. R., Martinez G. A. R., Lunelli B. H., Jardini A. L., Filho R. M.: Poly-lactic acid synthesis for application in biomedical devices - A review. Biotechnology Advances, 30, 321-328 (2011). https://doi.org/10.1016/j.biotechadv.2011.06.019

[26] Ghaffar T., Irshad M., Anwar Z., Aqil T., Zulifqar Z., Tariq A., Kamran M., Ehsan N., Mehmood S.: Recent trends in lactic acid biotechnology: A brief review on production to purification. Journal of Radiation Research and Applied Sciences, 7, 222-229 (2014). https://doi.org/10.1016/j.jrras.2014.03.002

[27] Mehta R., Kumar V., Bhunia H., Upadhyay S. N.: Synthesis of poly(lactic acid): A review. Journal of Macromolecular Science - Polymer Reviews, 45, 325-349 (2005) https://doi.org/10.1080/15321790500304148

[28] Lim L-T., Auras R., Rubino M.: Processing technologies for poly(lactic acid). Progress in Polymer Science, 33, 820-852 (2008). https://doi.org/10.1016/j.progpolymsci.2008.05.004

[29] Guo B., Ma P. X.: Synthetic biodegradable functional polymers for tissue engineering: A brief review. Science China Chemistry, 57, 490-500 (2014). https://doi.org/10.1007/s11426-014-5086-y

[30] Babak G., Hadi A.: Biodegradable polymers. in 'Biodegradation - Life of Science', (eds.: Chamy R., Rosenkranz F.), IntechOpen, 141-185 (2013). https://doi.org/10.5772/56230
[31] Park S. J., Lee K. Y., Ha W. S., Park S. Y.: Structural changes and their effect on mechanical properties of silk fibroin/chitosan blends. Journal of Applied Polymer Science, 74, 2571-2575 (1999).

https://doi.org/10.1002/(SICI)10974628(19991209)74:11<2571::AID-APP2>3.0.CO;2-A

[32] Kweon H., Ha H. C., Um I. C., Park Y. H.: Physical properties of silk fibroin/chitosan blend films. Journal of Applied Polymer Science, 80, 928-934 (2001). https://doi.org/10.1002/app.1172

[33] Lee S. M., Cho D., Park W. H., Lee S G., Han O. S., Drzal L. T.: Novel silk/poly(butylene succinate) biocomposites: The effect of short fibre content on their mechanical and thermal properties. Composites Science and Technology, 65, 647-657 (2005). https://doi.org/10.1016/j.compscitech.2004.09.023

[34] Lee K-G., Kweon H. Y., Yeo J-H., Woo S-O., Lee J-H., Park Y. H.: Structural and physical properties of silk fibroin/alginate blend sponges. Journal of Applied Polymer Science, 93, 2174-2179 (2004). https://doi.org/10.1002/app.20714

[35] Shibata M., Ozawa K., Teramoto N., Yosomiya R., Takeishi H.: Biocomposites made from short abaca fiber and biodegradable polyesters. Macromolecular Materials and Engineering, 288, 35-43 (2003). https://doi.org/10.1002/mame.200290031

[36] Lee S-H., Wang S.: Biodegradable polymers/bamboo fiber biocomposite with bio-based coupling agent. Composites Part A: Applied Science and Manufacturing, 37, 80-91 (2006).

https://doi.org/10.1016/j.compositesa.2005.04.015

[37] Mathew A. P., Oksman K., Sain M.: Mechanical properties of biodegradable composites from poly lactic acid (PLA) and microcrystalline cellulose (MCC). Journal of Applied Polymer Science, 97, 2014-2025 (2005). https://doi.org/10.1002/app.21779

[38] Serizawa S., Inoue K., Iji M.: Kenaf-fiber-reinforced poly(lactic acid) used for electronic products. Journal of Applied Polymer Science, 100, 618-624 (2006). https://doi.org/10.1002/app.23377

[39] Cheung H., Lau K.: Study on a silkworm silk siber / biodegradable polymer biocomposite. in 'Proceeding of $16^{\text {th }}$ International Conference on Composite Materials. Kyoto, Japan' TuGA1-01/1-TuGA1-01/9 (2007).

[40] Ho M. P., Wang H., Ho C. K., Lau K. T.: A study on the dynamic mechanical properties of silk fibre composites. Advanced Materials Research, 410, 106-109 (2011). https://doi.org/10.4028/www.scientific.net/amr.410.106

[41] Ho M-P., Wang H., Lee J-H., Ho C-K., Lau K-T., Leng J., Hui D.: Critical factors on manufacturing processes of natural fibre composites. Composites Part B: Engineering, 43, 3549-3562 (2012).

https://doi.org/10.1016/j.compositesb.2011.10.001 
[42] Kang M. K., Lee W. I., Hahn H. T.: Formation of microvoids during resin-transfer molding process. Composites Science and Technology, 60, 2427-2434 (2000). https://doi.org/10.1016/S0266-3538(00)00036-1

[43] Harris B.: Engineering composite materials. The Institute of Materials, London (1999).

[44] Callister W. D.: Materials science and engineering-An introduction. Wiley-VCH, New York (2006).

[45] Chung D. D. L.: Composite materials : Science and applications. Springer, London (2010)

[46] Daramola O. O., Akintayo O. S., Adewole T. A., Talabi H. K.: Mechanical properties and water absorption behaviour of polyester/soil-retted banana fibre (SRBF) composites. Annals of Faculty Engineering Hunedoara, International Journal of Engineeering, 1, 183 190 (2017).

[47] Daramola O. O., Akintayo O. S.: Mechanical properties of epoxy matrix composites reinforced with green silica particles. ANNALS of Faculty Engineering Hunedoara - International Journal of Engineering, 4, 167 174 (2017).

[48] Daramola O. O., Akintayo O. S.: Water absorption characteristics of epoxy matrix composites reinforced with green silica particles. Leonardo Electronic Journal of Practices and Technologies, 17, 215-232 (2018).

[49] Bai J.: Advanced fibre-reinforced polymer (FRP) composites for structural applications. Woodhead Publishing, Cambridge (2013).

[50] Matuana L. M., Balatinecz J. J., Sodhi R. N. S., Park C. B.: Surface characterization of esterified cellulosic fibers by XPS and FTIR spectroscopy. Wood Science and Technology, 35, 191-201 (2001). https://doi.org/10.1007/s002260100097

[51] Ho M. P.: Strengthening mechanism and bio-degradability of a silk-based polymer composite. PhD Thesis, University of Southern Queensland, Toowoomba (2012).

[52] Khoathane M. C., Sadiku E. R., Agwuncha C. S.: Surface modification of natural fiber composites and their potential applications. in 'Surface modification of biopolymers'. (eds.: Thakur V. K., Singha A. S.) John Wiley \& Sons Inc., New Jersey, 1, 370-400 (2015). https://doi.org/10.1002/9781119044901.ch14

[53] Rachini A., Le Troedec M., Peyratout C., Smith A.: Chemical modification of hemp fibers by silane coupling agents. Journal of Applied Polymer Science, 123, 601-610 (2012). https://doi.org/10.1002/app.34530

[54] Chaivan P., Pasaja N., Boonyawan D., Suanpoot P., Vilaithong T.: Low-temperature plasma treatment for hydrophobicity improvement of silk. Surface and Coatings Technology, 193, 356-360 (2005). https://doi.org/10.1016/j.surfcoat.2004.08.144

[55] Jiang P., Liu H., Wang C., Wu L., Huang J., Guo C.: Tensile behavior and morphology of differently degummed silkworm (Bombyx mori) cocoon silk fibres. Materials Letters, 60, 919-925 (2006). https://doi.org/10.1016/j.matlet.2005.10.056
[56] Yuksek M., Kocak D., Beyit A., Merdan N.: Effect of degumming performed with different type of natural soaps and through ultrasonic method on the properties of silk fiber. Advances in Environmental Biology, 6, 801-808 (2012).

[57] Yamada H., Nakao H., Takasu Y., Tsubouchi K.: Preparation of undegraded native molecular fibroin solution from silkworm cocoons. Materials Science and Engineering C, 14, 41-46 (2001). https://doi.org/10.1016/s0928-4931(01)00207-7

[58] Kluge J. A., Rabotyagova O., Leisk G. G., Kaplan D. L.: Spider silks and their applications. Trends in Biotechnology, 26, 244-251 (2008).

https://doi.org/10.1016/j.tibtech.2008.02.006

[59] Bershtein V. A., Egorova L. M., Yakushev P. N., Pissis P., Sysel P., Brozova L.: Conductive mechanism of polymer/graphite conducting composites with low percolation threshold. Journal of Polymer Science, Part B: Polymer Physics, 40, 954-963 (2002) https://doi.org/10.1002/polb.10141

[60] Daramola O. O., Oladele I. O., Adewuyi B. O., Sadiku R., Agwuncha S. C.: Influence of submicron agro waste silica particles and vinyl acetate on mechanical properties of high density polyethylene matrix composites. The West Indian Journal of Engineering, 38, 96-107 (2015).

[61] Cheung H. Y., Dean J., Stearn B., Clyne T. W.: Characterisation on PLA - silk fibre composites for prosthetic applications. in 'Proceeding of the $15^{\text {th }}$ European Conference on Composite Materials, Venice, Italy' $\mathrm{p} 8$ (2012).

[62] Khanam P. N., Al-Maadeed M. A., Khanam P. N.: Silk as a reinforcement in polymer matrix composites. in 'Advances in silk science and technology' (ed.: Basu A.) Woodhead, Amsterdam, 143-170 (2015). https://doi.org/10.1016/B978-1-78242-311-9.00008-2

[63] Memon A., Nakai A.: Fabrication and mechanical properties of unidirectional composite of silk/PLA by compression molding. in 'Proceeding of the $19^{\text {th }}$ International Conference on Composite Materials, Montréal' p9 (2013).

[64] Mangat A. S., Singh S., Gupta M., Sharma R.: Experimental investigations on natural fiber embedded additive manufacturing-based biodegradable structures for biomedical applications. Rapid Prototyping Journal, 24, 1221-1234 (2018).

https://doi.org/10.1108/RPJ-08-2017-0162

[65] Kruth J. P.: Material incress manufacturing by rapid prototyping techniques. CIRP Annals - Manufacturing Technology, 40, 603-614 (1991). https://doi.org/10.1016/S0007-8506(07)61136-6

[66] Dickson A. N., Barry J. N., McDonnell K. A., Dowling D. P.: Fabrication of continuous carbon, glass and kevlar fibre reinforced polymer composites using additive manufacturing. Additive Manufacturing, 16, 146-152 (2017). https://doi.org/10.1016/j.addma.2017.06.004 
[67] Song Y., Li Y., Song W., Yee K., Lee K-Y., Tagarielli V. L.: Measurements of the mechanical response of unidirectional 3D-printed PLA. Materials and Design, 123, 154-164 (2017). https://doi.org/10.1016/j.matdes.2017.03.051

[68] Melenka G. W., Cheung B. K. O., Schofield J. S., Dawson M. R., Carey J. P.: Evaluation and prediction of the tensile properties of continuous fiber-reinforced 3D printed structures. Composite Structures, 153, 866875 (2016). https://doi.org/10.1016/j.compstruct.2016.07.018

[69] West A. P., Sambu S. P., Rosen D. W.: Process planning method for improving build performance in stereolithography. Computer-Aided Design, 33, 65-79 (2001) https://doi.org/10.1016/S0010-4485(00)00064-6

[70] Kruth J. P., Wang X., Laoui T., Froyen L.: Lasers and materials in selective laser sintering. Assembly Automation, 23, 357-371 (2003). https://doi.org/10.1108/01445150310698652

[71] Dudek P.: FDM 3D printing technology in manufacturing composite elements. Archives of Metallurgy and Materials, 58, 1415-1418 (2013). https://doi.org/10.2478/amm-2013-0186

[72] Wang X., Jiang M., Zhou Z., Gou J., Hui D.: 3D printing of polymer matrix composites: A review and prospective. Composites Part B: Engineering, 110, 442-458 (2017). https://doi.org/10.1016/j.compositesb.2016.11.034

[73] Gonçalves C., Gonçalves I. C., Magalhães F. D., Pinto A. M.: Poly(lactic acid) composites containing carbonbased nanomaterials: A review. Polymers, 9, 269/1290/37 (2017). https://doi.org/10.3390/polym9070269

[74] Yeon Y. K., Park H. S., Lee J. M., Lee J. S., Lee Y. J., Sultan M. T., Seo Y. B., Lee O. J., Kim S. H., Park C. H.: New concept of 3D printed bone clip (polylactic acid/hydroxyapatite/silk composite) for internal fixation of bone fractures. Journal of Biomaterials Science, Polymer Edition, 29, 894-906 (2018). https://doi.org/10.1080/09205063.2017.1384199

[75] Ning F., Cong W., Qiu J., Wei J., Wang S.: Additive manufacturing of carbon fiber reinforced thermoplastic composites using fused deposition modeling. Composites Part B: Engineering, 80, 369-378 (2015). https://doi.org/10.1016/j.compositesb.2015.06.013

[76] Yasa E., Ersoy K.: Additive manufacturing of polymer matrix composites. in 'Aircraft technology' (ed.: Kushan M.) 147-169 (2018). https://doi.org/10.5772/intechopen.75628

[77] Chua C. K., Leong K. F., Lim C. S.: Rapid prototyping: Principles and application. World Scientific Publishing, Singapore (2003).
[78] Mohan V. B., Lau K-T., Hui D., Bhattacharyya D.: Graphene-based materials and their composites: A review on production, applications and product limitations. Composites Part B: Engineering, 142, 200-220 (2018).

https://doi.org/10.1016/j.compositesb.2018.01.013

[79] Shubhra Q. T. H., Alam A. K. M. M., Gafur M. A., Shamsuddin S. M., Khan M. A., Saha M., Saha D., Quaiyyum M. A., Khan J. A., Ashaduzzaman M.: Characterization of plant and animal based natural fibers reinforced polypropylene composites and their comparative study. Fibers and Polymers, 11, 725-731 (2010). https://doi.org/10.1007/s12221-010-0725-1

[80] Leng J., Lau K. T.: Multifunctional polymer nanocomposites. Taylor \& Francis, Florida (2011).

[81] Qiao F., Li D., Jin Z., Hao D., Liao Y., Gong S.: A novel combination of computer-assisted reduction technique and three dimensional printed patient-specific external fixator for treatment of tibial fractures. International Orthopaedics, 40, 835-841 (2016). https://doi.org/10.1007/s00264-015-2943-Z

[82] Zeng C., Xiao J., Wu Z., Huang W.: Evaluation of three-dimensional printing for internal fixation of unstable pelvic fracture from minimal invasive para-rectus abdominis approach: A preliminary report. International Journal of Clinical and Experimental Medicine, 8, 13039-13044 (2015).

[83] Perrone G. S., Leisk G. G., Lo T. J., Moreau J. E., Haas D. S., Papenburg B. J., Golden E. B., Partlow B. P., Fox S. E., Ibrahim A. M. S., Lin S. J., Kaplan D. L.: The use of silk-based devices for fracture fixation. Nature Communications, 5, 3385/1-3385/9 (2014). https://doi.org/10.1038/ncomms4385

[84] Cheung H-Y., Lau K-T., Pow Y-F., Zhao Y-Q., Hui D.: Biodegradation of a silkworm silk/PLA composite. Composites Part B: Engineering, 41, 223-228 (2010). https://doi.org/10.1016/j.compositesb.2009.09.004

[85] Ahmed I., Parsons A. J., Jones I. A., Walker G. S., Rudd C. D.: Biodegradable composite materials as bone regenerative implants. in 'Proceedings of the International Conference on Composite Materials, Edinburg, Scotland'p9 (2009).

[86] Suesat J., Ujjin S.: Effect of fabric structure and degumming conditions on the properties of PLA/silk blend. International Journal of Bioscience, Biochemistry and Bioinformatics, 3, 106-109 (2013).

[87] Ho M. P., Lau K. T., Wang H., Bhattacharyya D.: Characteristics of a silk fibre reinforced biodegradable plastic. Composites Part B: Engineering, 42, 117-122 (2011). https://doi.org/10.1016/j.compositesb.2010.10.007

[88] Facca A. G., Kortschot M. T., Yan N.: Predicting the tensile strength of natural fibre reinforced thermoplastics. Composites Science and Technology, 67, 24542466 (2007).

https://doi.org/10.1016/j.compscitech.2006.12.018 
[89] Craven J. P., Cripps R., Viney C.: Evaluating the silk/ epoxy interface by means of the microbond test. Composites Part A: Applied Science and Manufacturing, 31, 653-660 (2000). https://doi.org/10.1016/S1359-835X(00)00042-7

[90] Cheung H-Y.: Development of a silkworm silk fiberreinforced poly(lactic acid) biocomposite. $\mathrm{PhD}$ thesis, The Hong Kong Polytechnic University, 1-203 (2009).

[91] Cheung H-Y., Lau K-T.: Thermal properties of silk/poly(lactic acid) bio-composite. in 'Experimental analysis of nano and engineering materials and structures' (ed.: Gdoutos E. E.) Springer, Dordrecht, 821822 (2007).

https://doi.org/10.1007/978-1-4020-6239-1 408

[92] Huda M. S., Drzal L. T., Misra M., Mohanty A. K., Williams K., Mielewski D. F.: A study on biocomposites from recycled newspaper fiber and poly(lactic acid). Industrial and Engineering Chemistry Research, 44, 5593-5601 (2005).

https://doi.org/10.1021/ie0488849

[93] Agrawal C. M., Niederauer G. G., Athanasiou K. A.: Fabrication and characterization of PLA-PGA orthopedic implants. Tissue Engineering, 1, 241-252 (2007). https://doi.org/10.1089/ten.1995.1.241

[94] Dahham O. S., Hamzah R., Abu Bakar M., Zulkepli N. N., Ting S. S., Omar M. F., Adam T., Muhamad K., Dahham S. S.: Synthesis and structural studies of an epoxidized natural rubber/titania (ENR-50/TiO 2 ) hybrid under mild acid conditions. Polymer Testing, 65, 10-20 (2018).

https://doi.org/10.1016/j.polymertesting.2017.11.005

[95] Alakrach A. M., Noriman N. Z., Alsaadi M. A., Sam S. T., Pasbakhsh P., Dahham O. S., Shayfull Z.: Thermal properties of PLA/HNTs composites: Effect of different halloysite nanotube. AIP Conference Proceedings, 2030, 020052/1-020052/7 (2018).

https://doi.org/10.1063/1.5066693

[96] Ho M. P., Wang H., Lau K. T., Leng J.: Effect of silk fiber to the mechanical and thermal properties of its biodegradable composites. Journal of Applied Polymer Science, 127, 2389-2396 (2013).

https://doi.org/10.1002/app.37539

[97] Saviane A., Romoli O., Bozzato A., Freddi G., Cappelletti C., Rosini E., Cappellozza S., Tettamanti G., Sandrelli F.: Intrinsic antimicrobial properties of silk spun by genetically modified silkworm strains. Transgenic Research, 27, 87-101 (2018).

https://doi.org/10.1007/s11248-018-0059-0

[98] Basal G., Altıok D., Bayraktar O.: Antibacterial properties of silk fibroin/chitosan blend films loaded with plant extract. Fibers and Polymers, 11, 21-27 (2010). https://doi.org/10.1007/s12221-010-0021-0

[99] Bonilla J., Fortunati E., Vargas M., Chiralt A., Kenny J. M.: Effects of chitosan on the physicochemical and antimicrobial properties of PLA films. Journal of Food Engineering, 119, 236-243 (2013). https://doi.org/10.1016/j.jfoodeng.2013.05.026
[100] Li G., Qin S., Zhang D., Liu X.: Preparation of antibacterial degummed silk fiber/nano-hydroxyapatite/ polylactic acid composite scaffold by degummed silk fiber loaded silver nanoparticles. Nanotechnology, 30, 295101/1-295101/24 (2019).

https://doi.org/10.1088/1361-6528/AB13DF

[101] Zhang P., Qin J., Zhang B., Zheng Y., Yang L., Shen Y., Zuo B., Zhang F.: Gentamicin-loaded silk/nanosilver composite scaffolds for MRSA-induced chronic osteomyelitis. Royal Society Open Science, 6, 182102/1182102/10 (2019).

https://doi.org/10.1098/rsos.182102

[102] Jing J., Liang S., Yan Y., Tian X., Li X.: Fabrication of hybrid hydrogels from silk fibroin and tannic acid with enhanced gelation and antibacterial activities. ACS Biomaterials Science and Engineering, 5, 4601-4611 (2019).

https://doi.org/10.1021/acsbiomaterials.9b00604

[103] Chitichotpanya P., Pisitsak P., Chitichotpanya C.: Sericin-copper-functionalized silk fabrics for enhanced ultraviolet protection and antibacterial properties using response surface methodology. Textile Research Journal, 89, 1166-1179 (2019).

https://doi.org/10.1177/0040517518764010

[104] Yin G-B., Zhang Y-Z., Wang S-D., Shi D-B., Dong Z-H., Fu W-G.: Study of the electrospun PLA/silk fibroin-gelatin composite nanofibrous scaffold for tissue engineering. Journal of Biomedical Materials Research Part A, 93, 158-163 (2010). https://doi.org/10.1002/jbm.a.32496

[105] Pan Z-N., Pan Z-J.: The properties of plain satin-like PLA/silk mixed fabrics. Journal of Textile Engineering and Fashion Technology, 1, 28-31 (2017).

https://doi.org/10.15406/jteft.2017.01.00007

[106] Feng X., Pan Z., Di S., Chen Z., Chen M.: Wearable performances of lightweight PHA/PLA fiber and spun silk blended fabrics. Journal of Textile Engineering and Fashion Technology, 1, 62-66 (2017). https://doi.org/10.15406/jteft.2017.01.00012

[107] Butbunchu N., Pathom-Aree W.: Actinobacteria as promising candidate for polylactic acid type bioplastic degradation. Frontiers in Microbiology, 10, 2834/12834/10 (2019). https://doi.org/10.3389/fmicb.2019.02834

[108] Pritchard E. M., Valentin T., Panilaitis B., Omenetto F., Kaplan D. L.: Antibiotic-releasing silk biomaterials for infection prevention and treatment. Advanced Functional Materials, 23, 854-861 (2013). https://doi.org/10.1002/adfm.201201636

[109] Huang T., Qian Y., Wei J., Zhou C.: Polymeric antimicrobial food packaging and its applications. Polymers, 11, 560/1-560/18 (2019). https://doi.org/10.3390/polym11030560

[110] Tawakkal I. S. M. A., Cran M. J., Miltz J., Bigger S. W.: A review of poly(lactic acid)-based materials for antimicrobial packaging. Journal of Food Science, 79, 1477-1490 (2014). https://oi.org/10.1111/1750-3841.12534 
[111] Pawar R. P., Tekale S. U., Shisodia S. U., Totre J. T., Domb A. J.: Biomedical applications of poly(lactic acid). Recent Patents on Regenerative Medicine, 4, 40-51 (2014).

https://doi.org/10.2174/2210296504666140402235024

[112] Holland C., Numata K., Rnjak-Kovacina J., Seib F. P.: The biomedical use of silk: Past, present, future. Advanced Healthcare Materials, 8, 1800465/1-1800465/26 (2019)

https://doi.org/10.1002/adhm.201800465

[113] Spiridon I., Ursu R. G., Spiridon I. A. C.: New polylactic acid composites for packaging applications: Mechanical properties, thermal behavior, and antimicrobial activity. International Journal of Polymer Analysis and Characterization, 20, 681-692 (2015).

https://doi.org/10.1080/1023666X.2015.1081131

[114] Wu M-H., Zhu L., Zhou Z-Z., Zhang Y-Q.: Coimmobilization of naringinases on silk fibroin nanoparticles and its application in food packaging. Journal of Nanoparticles, 2013, 901401/1-901401/5 (2013).

https://doi.org/10.1155/2013/901401

[115] Marelli B., Brenckle M. A., Kaplan D. L., Omenetto F. G.: Silk fibroin as edible coating for perishable food preservation. Scientific Reports, 6, 25263/1-25263/11 (2016) https://doi.org/10.1038/srep25263

[116] Turalija M., Bischof S., Budimir A., Gaan S.: Antimicrobial PLA films from environment friendly additives. Composites Part B: Engineering, 102, 94-99 (2016). https://doi.org/10.1016/j.compositesb.2016.07.017

[117] Öz A., Süfer O., Çelebi Sezer Y.: Poly (lactic acid) films in food packaging systems. Food Science and Nutrition Technology, 2, 1-5 (2017).

[118] Siracusa V., Blanco I., Romani S., Tylewicz U., Rocculi P., Rosa M. D.: Poly(lactic acid)-modified films for food packaging application: Physical, mechanical, and barrier behavior. Journal of Applied Polymer Science, 125, 390-401 (2012).

https://doi.org/10.1002/app.36829
[119] Liu W., Zhou J., Ma Y., Wang J., Xu J.: Fabrication of PLA filaments and its printable performance. IOP Conference Series: Materials Science and Engineering, 275, 012033/1-012033/6 (2017). https://doi.org/10.1088/1757-899X/275/1/012033

[120] Uawongsuwan P., O-Charoen N., Hamada H.: Mechanical properties of natural fibers reinforced poly(lactic acid) based biocomposites. in 'Proceeding of the $19^{\text {th }}$ International Conference on Composite Materials, Montréal, Canada' p8 (2013).

[121] Holbery J., Houston D.: Natural-fiber-reinforced polymer composites in automotive applications. The Journal of the Minerals, Metals and Materials Society (TMS). 58, 80-86 (2006). https://doi.org/10.1007/s11837-006-0234-2

[122] Hargitai H., Rácz I., Anandjiwala R. D.: Development of hemp fiber reinforced polypropylene composites. Journal of Thermoplastic Composite Materials, 21, 165-174 (2014).

https://doi.org/10.1177/0892705707083949

[123] Jayabal S., Sivanarutchelvan G.: Prediction of thrust force and torque using regression model in drilling of natural fibre reinforced composites. in 'Proceeding of the National Conference on Discover Real Engineers and Mechanical Simulations (DREAMS), Perambalur, India' p9 (2009).

[124] Ahmad I., Baharum A., Abdullah I.: Effect of extrusion rate and fiber loading on mechanical properties of twaron fiber-thermoplastic natural rubber (TPNR) composites. Journal of Reinforced Plastics and Composites, 25, 957-965 (2006). https://doi.org/10.1177/0731684406065082

[125] Ku H., Wang H., Pattarachaiyakoop N., Trada M.: A review on the tensile properties of natural fiber reinforced polymer composites. Composites Part B: Engineering, 42, 856-873 (2011).

https://doi.org/10.1016/j.compositesb.2011.01.010

[126] Ho M. P., Lau K. T., Wang H., Bhattacharyya D.: Mechanical properties of an injected silk fibre reinforced PLA composite. in 'Proceeding of the $19^{\text {th }}$ International Symposium on Processing and Fabrication of Advanced Materials (PFAM XIX), Auckland, New Zealand' Vol 19, 885-894 (2011). 